\title{
4D Printing of Materials for the Future: Opportunities and Challenges
}

Siddharth Joshi ${ }^{\mathrm{a}}$, Krishna Rawat ${ }^{\mathrm{a}}$, Karunakaran C ${ }^{\mathrm{a}}$, Vasudevan Rajamohan ${ }^{\mathrm{b}}$, Arun Tom Mathew ${ }^{\mathrm{a}}$, , Krzysztof Koziolc ${ }^{\mathrm{c}}$, Vijay Kumar Thakur ${ }^{\mathrm{c}}$, Balan A.S.S ${ }^{\mathrm{b}}$,

a School of Mechanical Engineering, Vellore Institute of Technology, Vellore, India.

${ }^{\mathrm{b}}$ Centre for Innovative Manufacturing Research, Vellore Institute of Technology, Vellore, India

${ }^{\mathrm{c}}$ Enhanced Composites and Structures Center, School of Aerospace, Transport and

Manufacturing, Cranfield University, UK

\# Head of Enhanced Composites and Structures Centre

Cranfield University

School of Aerospace, Transport and Manufacturing

Building 61, Cranfield, Bedfordshire, MK43 0AL, UK

*Associate Professor

Manufacturing Engineering Division

School of Mechanical and Building Sciences

Vellore Institute of Technology, Vellore

Mobile: +91 - 9789941487

Email: balan.sheytra@vit.ac.in 


\begin{abstract}
The concept of 4D printing involves the formation of complex three-dimensional structures having the ability to adopt different shapes and forms when subjected to different environmental stimuli. Some researchers simply view this technique as an extension of $3 \mathrm{D}$ printing or additive manufacturing with the added constraint of time. However, the unique shape change mechanism exhibited in this process is due to a combination of shape programming and the usage of smart active materials mostly polymers. This review article highlights the various smart materials, activation mechanisms and the shape-changing techniques employed in the 4D printing process. The potential of these shape-changing structures and their current applications in various biomedical and engineering fields is also explored. The article aims to emphasize the potential and viability of $4 \mathrm{D}$ printing and is directed towards providing an in-depth insight into the $4 \mathrm{D}$ printing process.
\end{abstract}

Keywords: 4D Printing, Shape Memory Polymers, Shape Change, Soft Robotics

Abbreviations: 3D, Three dimensional; ITOP, Integrated tissue-organ printer; VPRP, Variable property rapid prototyping; 4D, Four dimensional; USD, United States Dollar; 1D, One Dimensional; 4DP, Four dimensional printing; SMA, Shape memory alloy; Fe, Ferrous; Si, Silicon; Hf, Hafnium; Ni, Nickel; Mn, Manganese; Ti, Titanium; SMP, Shape Memory Polymer; $\mathrm{T}_{\mathrm{g}}$, Glass Transition Temperature; MHI, Mitsubishi Heavy Industries; UMAT, User Material Subroutine; TSMP, Triple Shape Memory Polymer; IPN, Interpenetrating Polymer Network; PEG, poly(ethylene glycol); pHEMA, poly(2-hydroxyethyl methacrylate); HEMA, 2-hydroxyethyl methacrylate; PNIPAAm, (Poly(N-isopropylacrylamide)); P $\mu$ SL, Projection Micro Stereolithography; PCN, Polymer Carbon Nanotube composite ; $\mathrm{Fe}_{3} \mathrm{O}_{4}$, Iron Oxide; ESO, Epoxidized Soyabean Oil; PCL, Polycaprolactone ;SLA, Stereolithography; FDM, Fused Deposition Modeling; EBM, Electron Beam Melting; SLM, Selective Laser Melting; DIW, Direct Ink Writing; UV, Ultraviolet; tBA, tert-Butyl acrylate; DEGDA, di(ethylene glycol) diacrylate; LED, Light Emitting Diode; P $\mu$ SL, Projection Micro Stereolithography; 2D, Two Dimensional; PAC, Printed Active Composites; 1W-1SM, One Way Shape Memory Effect; 2W-2SM, Two Way Shape Memory Effect; POSS, Polyhedral Oligomeric Silsesquioxane; wt \%, weight percentage; PLGA, Poly(L-lactic-co-glycolic acid); DUIF, deionized-ultrafiltrated; GelMA, gelatin methacrylate; NIPAAm, N-isopropylacrylamide; PEGDA, polyethylenglycol-diacrylate; PBS, phosphate buffered saline; CHEM, Cold Eibernated Elastic Memory; DARPA, Defense Advanced Research Projects Agency; EMC, Elastic Memory Composite; STENG, SMP based triboelectric nanogenerator; PEP, Printed Electronic Papercrafts

\title{
Introduction
}

\subsection{Additive Manufacturing}

Additive manufacturing or 3D (Three dimensional) printing involves layer by layer addition of material to form the desired shape [1]. The steady rise of 3D printing techniques over the last few decades can be attributed to their ability to print complicated shapes and the wide variety of 
materials they employ. The popularity of these techniques is mainly due to the freedom they offer during the design stage by allowing the designers to tinker and improvise freely to produce unique shapes and configurations [2].

In particular, 3D printing has found its niche in numerous biomedical sectors like tissue engineering and pharmaceutics. Several state of the art techniques employed for bioprinting have been developed and significant progress has been made in 3D bioprinting of human tissues and organs over the last decade [3]. Development of 3D printers such as the integrated tissue-organ printer (ITOP) has enabled stable fabrication of human-scale tissue construction by utilizing a combination of biodegradable polymers and hydrogels [4]. Several other types of printing techniques involving inkjet and extrusion-based printers have also been developed [5]. All these different techniques come with their own unique printing mechanisms, materials, applications and advantages and disadvantages [6]. There has been a continuous development of new and more efficient 3D printing techniques over the years. One of such techniques is variable property rapid prototyping (VPRP) which aims to tackle the limited material handling capacity of additive manufacturing. VPRP is not limited to the production of single material prototypes and can produce highly customizable prototypes with a range of ratios and mix grade [7].

\subsection{D Printing}

The next generation of printing techniques saw the use of smart materials to print structures which could change their shape with time as presented in Fig.1. This characteristic shape change adds a fourth dimension of time to the printing process which ultimately led to the development of 4D (Four-dimensional) printing techniques. Besides having the ability to alter the base shape after printing, 4D printing techniques also offer several advantages over traditional additive manufacturing. These include minimizing a variety of factors such as the assembly time, the net cost, number of components and the failure rate [8]. The primary difference between $3 \mathrm{D}$ and $4 \mathrm{D}$ printing is the static nature of the former technique. Unlike 3D printing, 4D printing allows the base material to transform into different shapes with time with the response to external stimuli. The study conducted by [9] highlights the differences between 3D and 4D printing techniques, the evolution of these technologies through the years and their potential in the different industrial sectors.

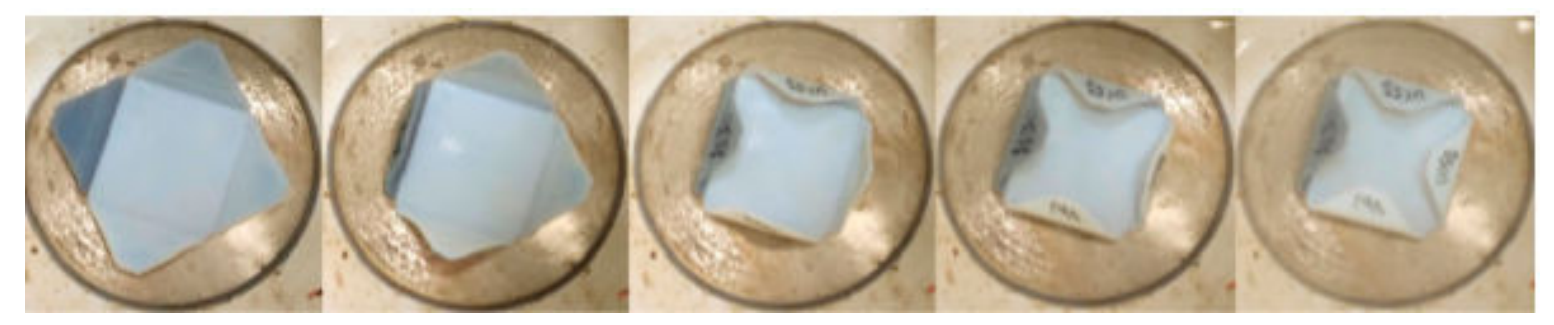

Fig. 1 Printed smart material exhibiting the shape-changing effect

(Reprinted with permission from [13], Copyright with License Number: 4615851131087) 
The concept of self-assembly which involves raw materials coming together and assembling themselves, rather than being fed into a machine for processing has often been used in conjunction with 4D printing [10]. However, 4D printing is not just restricted to self-assemblies. According to [11], the term 4D printing relates to the technique of using additive manufacturing on stimulusresponsive active materials which results in a physical or chemical change in their composition with time. This stimulus can be of either physical or chemical nature such as humidity, $\mathrm{pH}$, light intensity and temperature. As per market reports, the 4D printing sector would be worth about USD 313.1 million by 2025 [12]. The report attributes this exponential rise in the market to the high demand for 4D materials in military, defense, aerospace and healthcare industries.

\subsection{History of 4D Printing}

Significant research has been conducted on 4D printing due to its immense potential. Several studies are available which have focused on different constituents of the 4D printing process ranging from the materials employed in the printing techniques to the history of the technology itself. Fig. 2 provides statistical data for the research done on 4D printing in recent years. [13] provides a look into the evolution of $4 \mathrm{D}$ printing and highlights the different materials used in common 4D printing techniques. The study by [14] is focused on the advancement of 4D printing and the different methods adopted by the pioneers of this field. One such method adopted by Skylar Tibbits involved materials constituting of parts which expand at different rates. These materials stretch and fold to form different shapes when activated by the stimulus. With the aid of the company Stratasys, Tibbits evolved his printing technique to convert 2D (Two dimensional) and 1D (One dimensional) strands into 3D shapes. This technique employed water as an activating agent and was highly effective in shape programming of non-electric materials. Jerri Qi's research which dealt with shape programming of thermally responsive composites was a milestone in the field of 4D printing. When exposed to the appropriate temperature, these composites exhibited a shape memory effect which enabled them to form the desired 3D shape [15].

According to [16] there are three primary paradigms to 4D printing. The first approach employs a smart material which changes its shape to form new structures when acted upon by stimuli. The second approach relates to $3 \mathrm{D}$ printing of polymeric material which can act as a supporting structure for the growth of organic cells and tissue. This technique is employed primarily in bioprinting applications and requires a biodegradable base polymeric material which can break down once the tissue formation is complete. The last approach deals with self-assembly of small micro-sized smart particles which upon stimulation change their pattern. Several plans and strategies have also been designed to provide a suitable methodology for 4D printing. The 4DP (Four-dimensional plan) aims to provide a foundation for designing of $4 \mathrm{D}$ printed materials. The 4DP plan requires classification of smart material based upon the response provided by them when exposed to stimuli. The plan can potentially be improved by integration of additive manufacturing and computational frameworks [17]. 

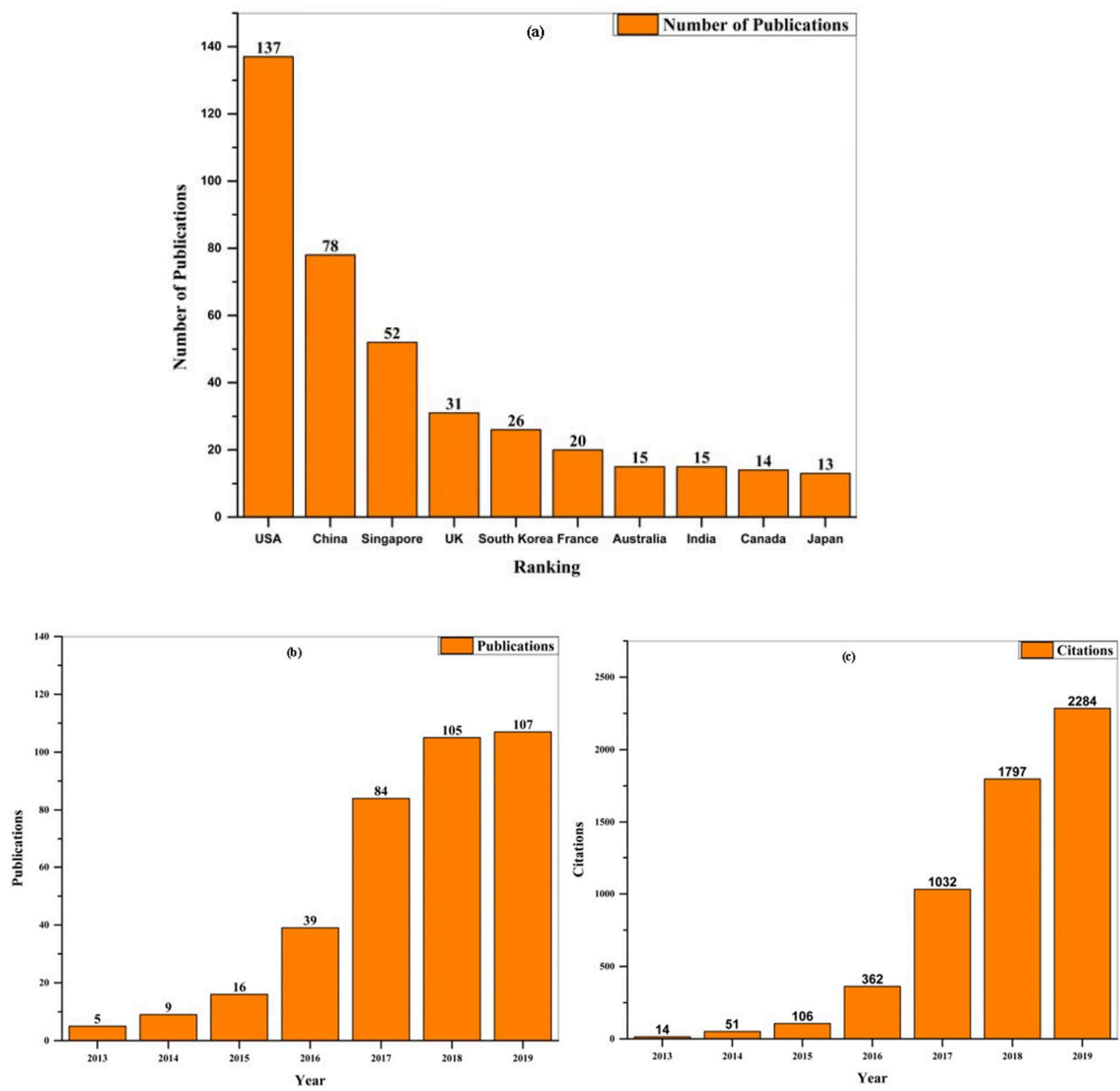

Fig. 2 Statistical data of 4D printing based research (a) Publication distribution for different countries (b) Publication distribution per year (c) Citation distribution per year (Plots are drawn as per web of science data collected from the year 2013 to 2019)

\subsection{Advancements in 4D Printing}

In recent years, a significant endeavor has been taken to develop efficient 4D printing platforms. An inkjet-based printer was used to print Bacillus Subtilis natto cells which would change their shape with varying relative humidity [18]. These active biofilms were then used to print various shape-changing structures like stimuli-responsive artificial plants and lamps. The print is a highly customizable open-source smart material printer which can be used to print a large variety of 
stimuli-responsive shape-changing materials [19]. It can employ a wide range of smart materials and has been successfully used to create stimuli-responsive constructs such as sweat responsive garments and biodegradable hydrogel-based drug delivery systems. 4D printing has been made easier with the development of softwares such as Project Cyborg by Autodesk Research and Kinematics by Nervous System [20]. These softwares allow visualization of the 4D printing project and help designers to fully realize their product even before the commencement of the development stage. The study by [21], provides analysis of the various types of softwares employed at the different development stages of the 4D printing process. The combined effort of all these softwares is essential for the efficient building of 4D products as presented in Fig.3.

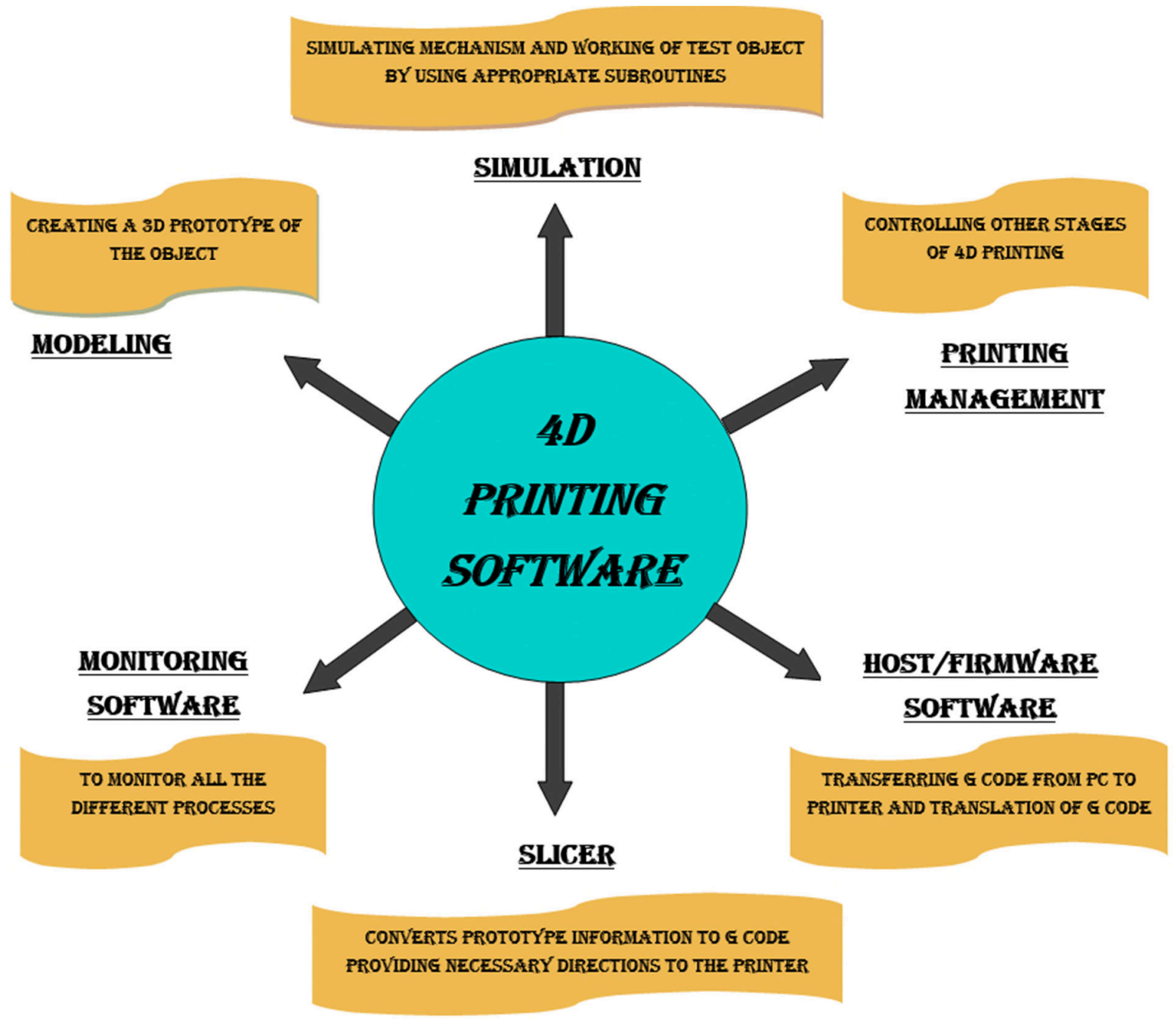

Fig. 3 4D Printing softwares and their applications

It is clear that 4D printing is not a simple printing process and requires a combination of several components. Generally, a 4D printing process uses a printing technique to print shape-changing structures by actuating a smart material in response to stimuli. Over the last decade, there has been a large number of reviews on 4D printing of smart materials. A large section of these reviews focuses on $4 \mathrm{D}$ printing in biomedical or a certain engineering domain. This review aims to serve 
as an intermediate by paying special emphasis to both the biomedical and structural applications of 4D printing technology. The review also focuses on certain active materials, the printing techniques and the actuation process employed to evoke the shape-changing mechanism.

\section{Active Materials}

\subsection{Shape Memory Alloy (SMA)}

Shape memory alloys (SMAs) are metal alloy systems which can exist in multiple unique phases or states when exposed to temperature or load change [22]. SMAs exhibit shape memory effect by which they retain their original shape even after severe deformation. SMAs exhibit superelastic behavior because they undergo a phase change transformation. This transformation has a forward and a reverse phase under which an austenite-martensite and a martensite-austenite transformation takes place. This transformation greatly increases the fracture toughness of the SMA [23]. In-depth study of fracture toughness mechanism proves that temperature has a pronounced effect in the toughening of SMA. Increasing temperature greatly reduces the stress intensity factor which contributes to an overall increase in the toughness of the SMA [24]. A volume contraction is also observed during this phase transformation. This volume contraction can potentially have a deleterious effect on the fracture properties of superelastic SMAs. Research conducted on this phenomenon proved that the forward transformation volume contraction decreases the strength of SMAs while the reverse transformation volume contraction has a negligible impact on their strength [25].

SMAs have become extremely common in engineering and medical sectors [26,27]. Iron-based SMAs like the Fe-Mn-Si alloy system has great potential in the civil engineering sector for repair and reinforcement of structures [28]. NiTiHf based SMAs have the ability to operate at very high temperatures and thus are ideal for aerospace and automotive applications [29]. Fig. 4 provides one such aerospace application of SMAs. NiMn based SMA systems which can be actuated by magnetic fields are fitting candidates for the production of actuators and sensors [30]. The review conducted by [31] serves as a catalog of the various applications of SMAs in the prevalent industrial and commercial domains. The review focusses on the application of SMAs in the biomedical, aerospace, automotive and robotic sectors. SMA based contraptions (implants, stents, guide wires and stents) are being widely used in medical sectors like neurology, orthopedics and cardiology. They are also being employed as actuators in aeronautical and robotic sectors due to their cost-effective nature and their shape morphing ability. The binary Ni-Ti SMA system, which is more commonly referred to as nitinol has become a major player in the biomedical field. Nitinol which is an alloy of 50\% Nickel and 50\% Titanium was discovered in the early 1960s and became popular in 1980s. A significant amount of research has been dedicated to ascertaining the shape memory effect and the thermomechanical properties of nitinol [32-37] but a considerably less amount of attention has been given to its failure mechanism. 

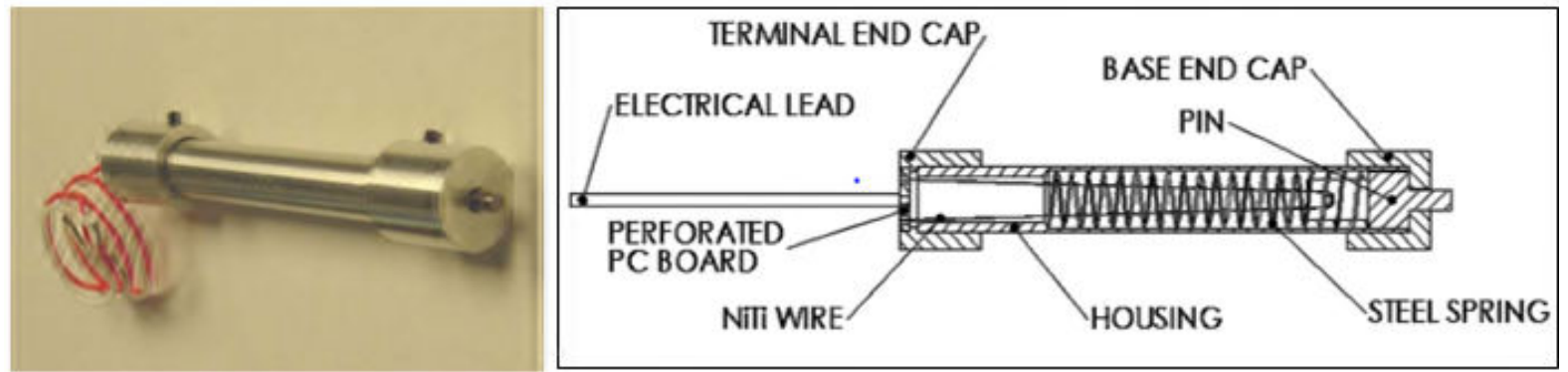

Fig. 4 SMA based pin puller for aerospace application

\section{(Reproduced from [22])}

Research conducted on the failure mechanism of notched Ni-Ti round bar SMA specimens displayed the negative effect of notches on the superelastic behavior of the material [38]. This can be related to the fact that the introduction of notches induces plastic strain which causes a loss in the superelastic properties of the specimen. Studies on the crack propagation and the cyclic crack growth resistance offered by Nitinol when exposed to different environments showed Nitinol to have low fatigue crack growth resistance and high crack growth rates in comparison to other biomedical alloys. These studies also showed the minimal impact of the environment on the crack growth rates of Nitinol [39]. The mechanical properties of Nitinol or any other titanium-based material, in general, have been shown to improve with nanoscale refinement. Nanostructuring of nitinol renders it more biocompatible and makes it a safer option for use in biomedical implants [40].

\subsection{Shape Memory Polymer (SMP)}

Shape memory polymers (SMPs) are smart materials which are capable of changing their shape in response to external stimuli [41]. The concept of shape memory polymer arose in Japan in 1984 when Nippon Zeon co-developed a polynorbornene based SMP. Tests conducted by the Kuraray and the Asahi Company led to the development of other SMPs which possessed a better range of transition temperature values $\left(\mathrm{T}_{\mathrm{g}}\right)$. These developments also led to the creation of the MHI Polyurethane SMP which had a wide range of transition temperature values $\left(\mathrm{T}_{\mathrm{g}}\right)$ and better processability [42]. The MHI Polyurethane SMP has many unique features and properties which makes it ideal for several scenarios. Studies have been conducted to analyze the moisture and thermal responsive properties of the MHI Polyurethane SMP in greater detail [43]. Important applications of this particular SMP include a thermal responsive Braille pen which allows modification of mistakes by employing a pointer heater which reverts the SMP back to its original state and moisture-responsive SMP stents which reacts and changes shape according to the moisture content. Fig. 5 displays the shape-changing capability of MHI Polyurethane SMP. 

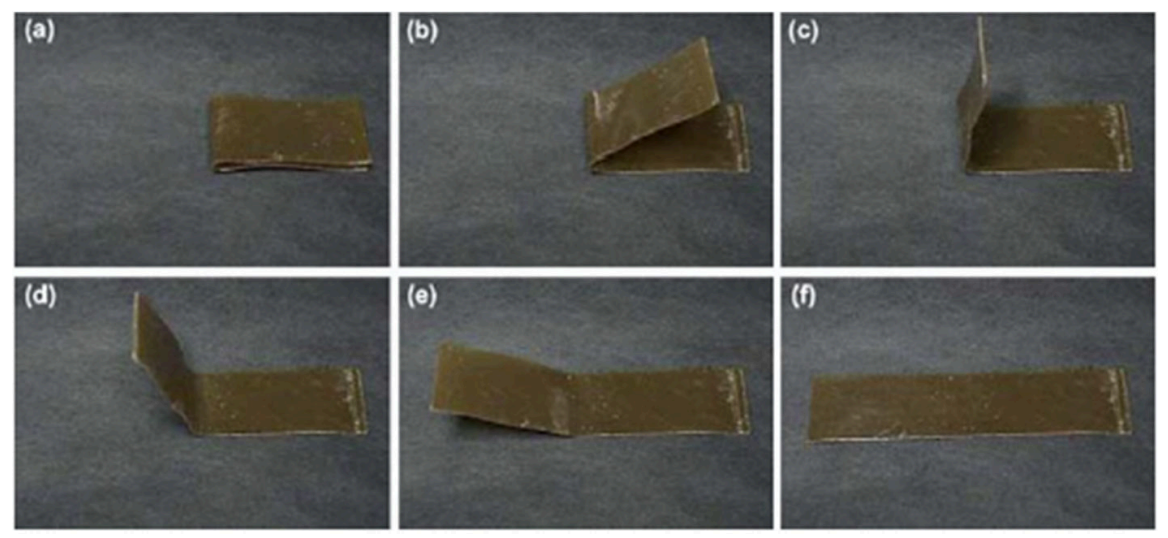

Fig. 5 Shape Recovery of Polyurethane SMP

\section{(Reprinted with permission from [43], Copyright with License Number: 4615870271018)}

The thermomechanical properties of SMPs have been investigated thoroughly using a variety of conventional (uniaxial tensile tests, cyclic tensile tests and creep tests) [44] and unconventional techniques (bulging, point deflection and nanoindentation tests) [45]. The history of SMPs, their shape-changing mechanism, common application and development through the ages have also been studied in great detail [46,47]. Both SMAs and SMPs are widely used shape memory materials. However, SMPs are lighter, more flexible and exhibit a greater degree of biocompatibility then SMAs [48]. SMPs can also recover a larger magnitude of strain and consume considerably less energy during the shape memory programming [49,50]. Fig. 6 shows the shape recovery cycle of an acrylate-based SMP.

SMPs are being widely used in aerospace and medical industries to form complex structures. Analytical simulations of such complex geometries require the formation of competent models which can predict the material behavior of these structures. One such model was incorporated in a user material subroutine (UMAT) in Abaqus with the aim of predicting the behavior of SMPs having complex geometries [51]. This subroutine was then used to analyze a variety of boundary value problems and was ultimately used to model the response of certain biomedical devices. The deformations induced in SMPs during the thermomechanical cycle have also been studied analytically. One such study proposed a new microstructure of SMPs which constituted of a constant active phase and a passive phase which cycled between free and frozen transformations [52]. Many other studies have been conducted to form constitutive models for predicting the thermomechanical properties, deformation mechanism, shape recovery mechanism and microstructure of SMPs.

Triple shape memory polymers (TSMPs) are SMPs which have the capacity to form and remember multiple shapes when exposed to stimuli. Generally, SMPs can oscillate between two primary shapes when exposed to stimuli. But TSMPs can also acquire a tertiary stage comprising of covalent cross-links [53]. A significant amount of research has been done on the properties and the shape-changing the programming of TSMPs [54-56]. 


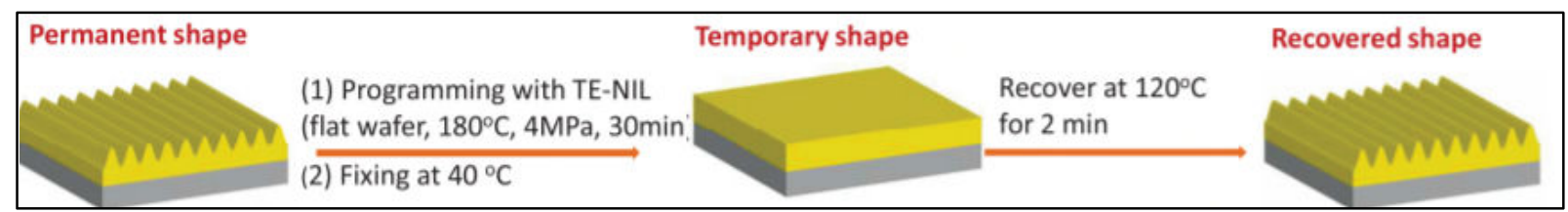

Fig. 6 Shape memory cycle of acrylate-based SMP

(Reprinted with permission from [50], Copyright with License Number: 4615860581635)

\subsection{Hydrogels}

Hydrophilic polymeric materials known as Hydrogels have become common active materials in 4D printing because of their ability to change their volume drastically with the response to stimuli [57]. However, they have a significant disadvantage in terms of their mechanical strength. Structures constituting hydrogels tend to be weak and extremely brittle. To combat this, they are generally infused with a secondary polymeric network. Interpenetrating network (IPN) hydrogels are one such extremely tough material composed of ionic and covalently bonded crosslinked polymeric networks [58]. Similarly structured hybrid hydrogel inks were used to 3D print hinges with analytically optimized bending characteristics [59]. Hydrogels infused with other polymers are used extensively in the field of biomedicine [60,61]. Hydrogels of crosslinked sodium alginate and PEG have been used to form highly flexible and biodegradable cellular constructs like kidney cells [62]. Hydrogel compounds have also been utilized in the fabrication of organic constructs like vascular networks and for wound healing regenerative medicines [63,64]. 3D scaffolds made from hydrogel inks comprising of crosslinked pHEMA and HEMA chains were used as culture platform for primary hippocampal neurons [65].

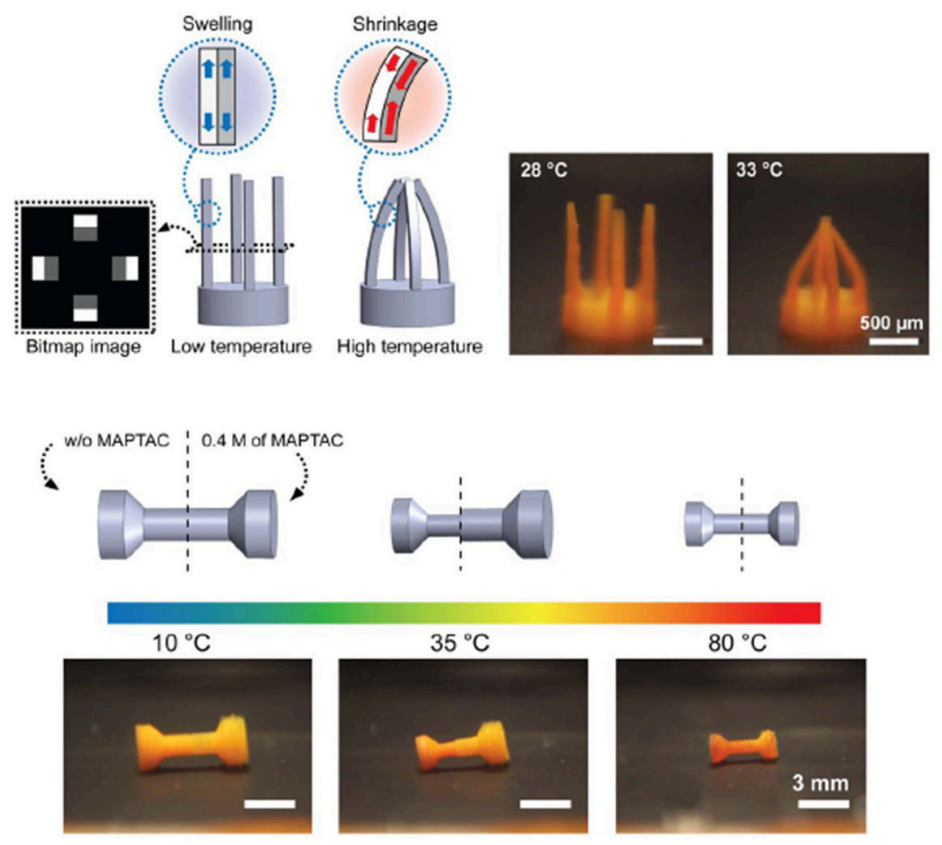

Fig. 7 PNIPAAm hydrogel-based structures

(Reproduced from [66]) 
Recently a new 3D printing technique was devised for printing PNIPAAm (Poly(N-isopropyl acrylamide)) hydrogels which can be utilized for a collection of biomedical (drug delivery, tissue engineering) and engineering (sensors and actuators) systems [66] as presented in Fig. 7. This technique named projection micro stereolithography $(\mathrm{P} \mu \mathrm{SL})$ provides an efficient and costeffective method to print PNIPAAm based 3D structures.

\subsection{Other materials}

The active material which is used in 4D printing is not just limited to singular materials like SMPs or hydrogels. Non-active and multi-material structures of suitable composition can also display a shape-changing effect when observed over time [67].

Addition of carbon nanotubes into polymeric materials in extremely small amounts results in the formation of Polymer carbon nanotube composites (PCNs). These nanotubes induce certain unique mechanical and electrical characteristics to the PCN which allow the material to adopt different shape-changing actuation schemes [68]. This can be utilized to create a variety of PCNs each of which can exhibit unique stimuli-responsive behavior and thus can be used for a wide range of applications. Polymers combined with $\mathrm{Fe}_{3} \mathrm{O}_{4}$ nanoparticles and carbon nanotubes have been used to obtain a large configuration of shapes [69]. This is achieved by introducing heat at different radio frequencies. For this particular configuration, a total of five different polymeric shapes can be obtained during the recovery process.

Addition of graphene nanocomposites to thermally activated SMPs increased the strength of the composite and allowed a higher degree of deformation without fiber breakage [70]. The addition of graphene lowers the crosslinking density of the SMP thereby making the composite extremely tough. These graphene nanocomposite based SMP systems are an ideal candidate for the development of self morphing aircraft structures. Graphene-based compounds have also been explored as potential smart materials because of their agreeable mechanical properties, excellent thermal and electrical conductivities and relatively inexpensive nature. Due to these excellent properties, graphene-based smart materials have been used to fabricate sensors, actuators, photovoltaic devices and drug delivery biomedical devices [71-74]. [75] provides an in-depth review of the variety of smart materials fabricated from graphene-based compounds and the techniques used for their fabrication.

Generally, ceramics are extremely brittle and thus fail easily at strains of low magnitude. However certain ceramics with a fine structure and few grain junctions can handle larger magnitudes of stress without cracking and thus can potentially serve as smart materials. The high strength and the refractory nature of these compounds make them ideal for temperature-activated shape memory applications [76]. Shape memory materials have also been generated from organic sources like plant oil. One such example is epoxidized soyabean oil (ESO) and polycaprolactone (PCL) based compound [77]. This material has enhanced mechanical properties and can be used as a biodegradable smart material. The high degree of biodegradability and the superior mechanical properties exhibited by this compound can be attributed to its PCL component. This ESO/PCL 
based shape memory material also displays excellent shape memory and recovery behavior and is extremely reusable, making it ideal for shape-changing smart devices.

\section{4D printing techniques}

Over the last decade, 3D printing methods have been adapted for the printing of active structures. The chapter on 4D printing and its biomedical applications in "3D and 4D Printing in Biomedical Applications: Process Engineering and Additive Manufacturing" lays down all the different 3D printing techniques which are being used in conjunction with smart materials to obtain shapechanging products [78]. Some of these include traditional and contemporary methods like in situ fabrication, extrusion-based methods, stereolithography (SLA), fused deposition modeling (FDM), electron beam melting (EBM), inkjet printing and selective laser melting (SLM) [79-81]. Fig. 8 shows the 4D printing techniques discussed in this review.
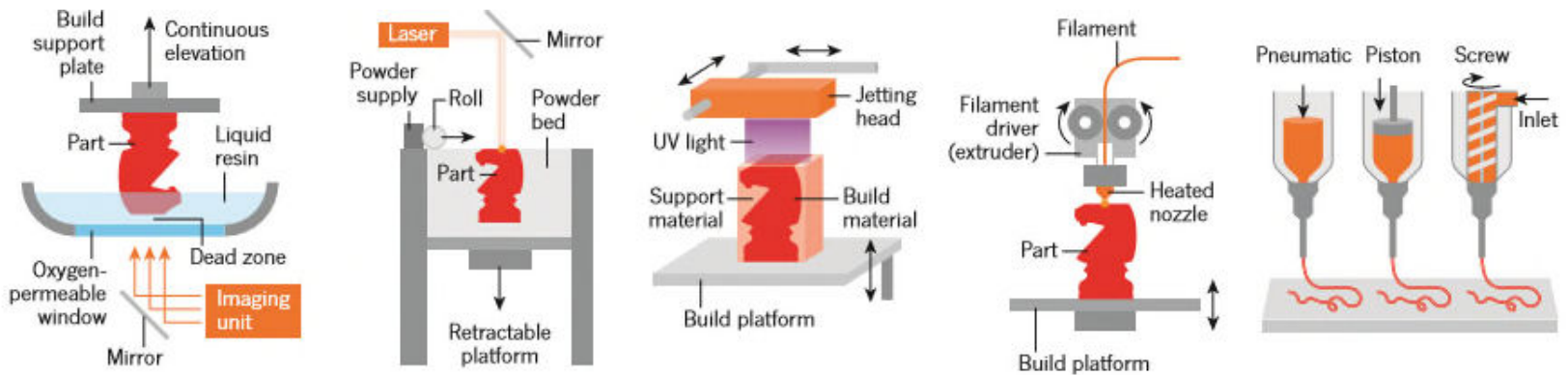

Fig. 8 Traditional light and ink-based 3D printing methods

\section{(Reprinted with permission from [81], Copyright with License Number: 4615880329578)}

Adapting 3D techniques for 4D printing of smart materials generally requires a few modifications to the former. FDM techniques were modified by adding an air circulation system to successfully print smart materials [82]. The wind provided from the air circulation system helps to cool down the SMP below its glass transition temperature.

Inkjet printing is a non-contact technique which reads the structural data from a computer and reconstructs it physically by deposition of small ink drops [83]. Inkjet printing is a highly biocompatible process. According to studies by [84], cells manufactured via thermal inkjet printers do not exhibit high stress and can be printed very precisely with greater than $30 \%$ transfection efficiency. Other important applications of this technique include bioprinting of living cells on culture disks [85] and 4D origami-based frequency selective surface [86].

Fused deposition modeling (FDM) technique involves extruding a melted base material through a nozzle to form 3D structures in a layer by layer manner. Due to the simplistic nature of this technique, it has been used for a variety of 4D printing applications such as manufacturing SMP 
based robotic grippers and dog bone samples [87,88]. FDM offers several basic advantages over the more contemporary 4D printing techniques. It is easily upgradable and relatively inexpensive when compared to other modern techniques like polyjet printing. However, unlike polyjet printing, FDM cannot produce a smooth highly finished product [89]. Recently FDM techniques have also been used successfully to print self-folding and self-coiling metamaterials [90].

Direct ink writing (DIW) employs nozzles to deposit viscoelastic inks under large pressure to form 3D structures [91]. DIW printers have been employed in the biomedical field for the purpose of printing high strength biodegradable scaffolds and for tissue engineering [92,93]. UV assisted DIW process has been used to print highly stretchable self-healing shape memory elastomers [94]. These elastomers can potentially serve as biomedical repair devices due to their self-healing properties.

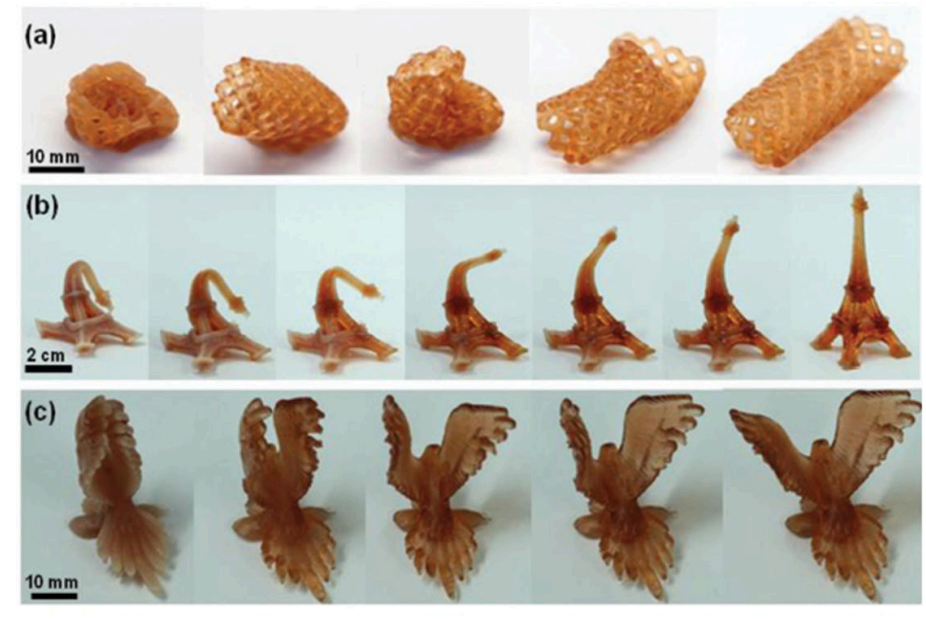

Fig. 9 Shape changing structures printed using SLA

(Reprinted with permission from [95], Copyright with License Number: 4615880573475)

The technique of stereolithography (SLA) is one of the more common methods employed for printing SMPs. It has very high accuracy and can employ a wide range of materials. It utilizes a laser to polymerize the material layer by layer to form the 3D structure [95] as shown in Fig. 9 . Highly detailed studies of SLA technique highlighting the manufacturing procedure, the base materials and its applications have been conducted [96]. Thermally activated polymers based on tBA-co-DEGDA networks have been developed using SLA techniques [97]. The finished product obtained via SLA was found to have $82 \%$ higher elongation than that obtained using industrialgrade SMPs. Efforts have been made to develop inexpensive and energy-efficient stereolithography techniques such as UV-LED based stereolithography [98]. Another modified stereolithography technique, projection micro stereolithography $(\mathrm{P} \mu \mathrm{SL})$ has been used to fabricate multi-material SMP structures like grippers, drug delivery systems and flowers [99]. 


\section{Shape change mechanism}

The idea of utilizing the change in the shape of a material is not novel to 4D printing. Several shape programming techniques exist which utilize this particular feature. 2D polymeric sheets can be easily converted to 3D sheets by employing certain strategies. Polymeric sheets are preferred for these processes because they are lightweight, cost-effective and extremely flexible [100]. Table. 1 presents several 2D to $3 \mathrm{D}$ transformation strategies. This $2 \mathrm{D}$ to $3 \mathrm{D}$ shape-changing techniques have real-world potential because of the compactness and the low transportation costs they provide. Similar techniques have been explored for edibles wherein 2D food materials can be easily transformed to 3D shapes by water absorption [101].

Table. 1 2D to 3D transformation strategies

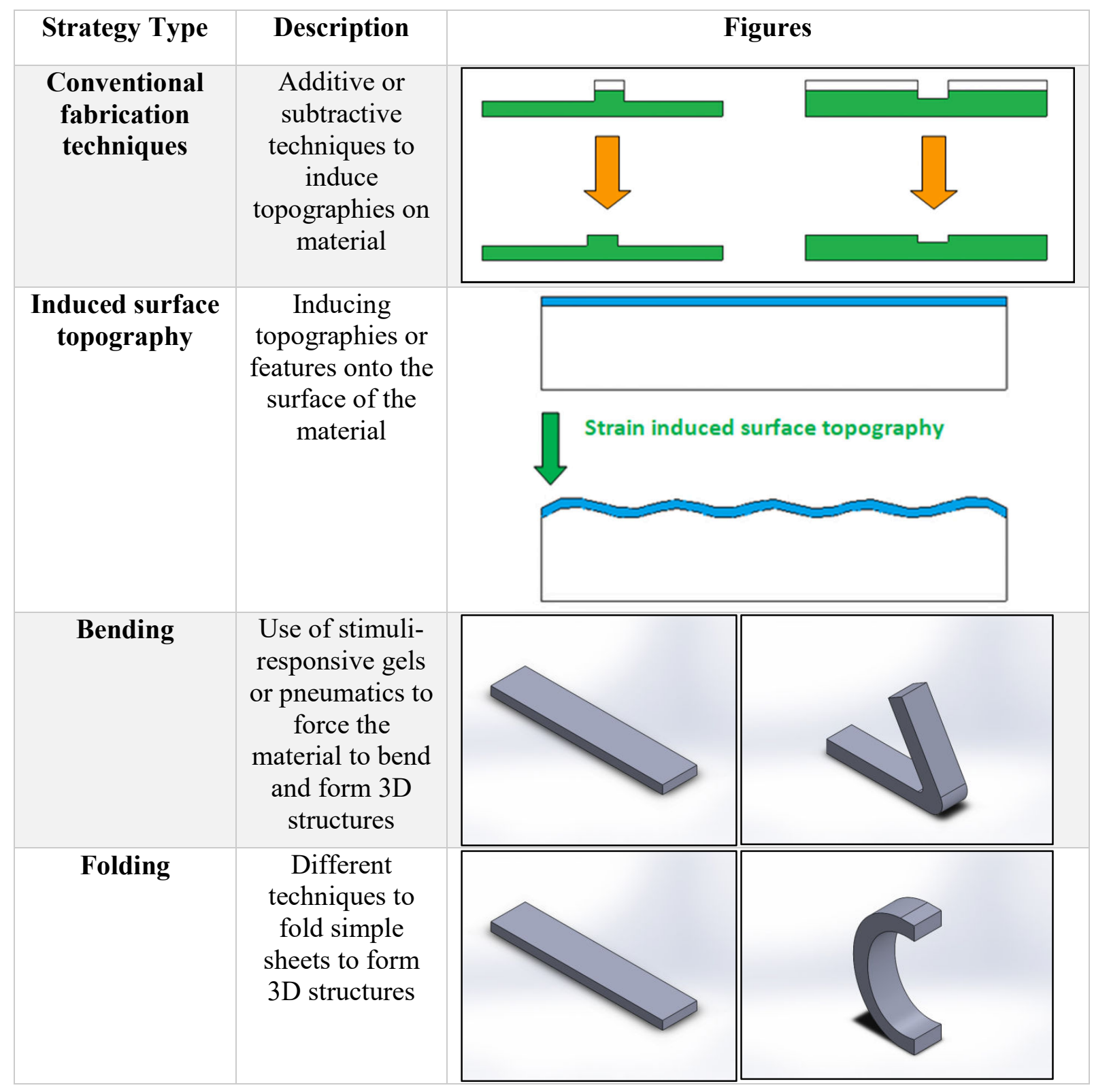




\subsection{Active origami and self-folding techniques}

Active origami basically relates to the use of specific smart material to create self-actuating structures, which are capable of folding and unfolding like the real world origami paper techniques. This technique can potentially provide a solution to large volume or storage space engineering problems by designing structures which can fold and occupy smaller spaces. Hinges based on polymeric sheets combined with printed active composites (PAC) have been used to create active origami structures [102]. When exposed to external stimuli, these conjoined sheets would fold into the desired shape to form complex structures like 3D boxes and pyramids. Active origami techniques have also been employed to create a variety of 3D structures from origami tubes which have real-world application in the field of robotics, actuators and for space deployment [103].

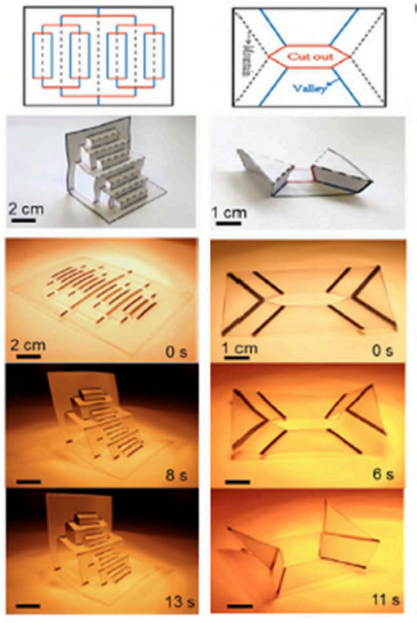

(a)
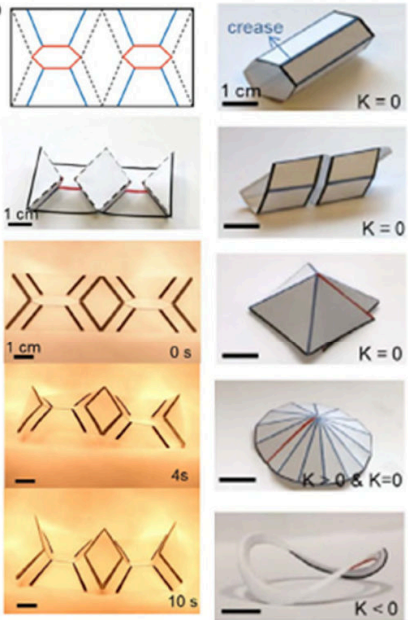

-

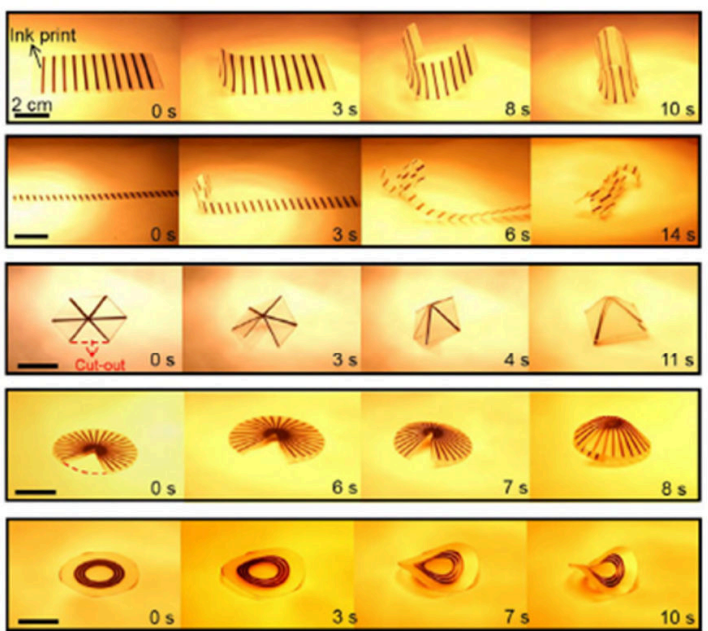

(b)

Fig. 10 (a) Kirigami techniques (b) Origami techniques

\section{(Reprinted with permission from [106], Copyright with License Number: 4615880960246)}

Active origami techniques have been used to form 3D spherical structures from 2D parylene-C films [104]. This technique can be implemented to form retinal implants which can change shape after being surgically inserted into the eye as $2 \mathrm{D}$ sheets. Active origami has also been employed successfully for the formation of self-folding machines like robots [105]. A 2D polymeric sheet embedded with electronics was transformed into a 3D robotic structure by self-folding along the hinges. This particular application shows the rapid and inexpensive nature of employing origami techniques for building mechanical systems.

Light actuated self-folding has been employed by [106] for shape programming of thin polymeric sheets. This particular method replicates the origami and kirigami techniques of folding and cutting paper to obtain the desired shape. The polymeric sheets are coated with black ink which folds to produce origami structure or pop up kirigami structures when exposed to near-infrared light. The various geometries and configurations obtained via light actuated self-folding are presented in Fig. 10. In general, self-folding techniques have been extensively used to form shape-changing structures. SMP based materials which exhibit self-folding when exposed to thermal stimuli have been designed to form complex helical hinge structures [107]. A collision index was designed for 
the prediction of the collision during self-folding. Managing these collisions would enable the SMP to follow the appropriate folding sequence without restrictions. Hydrogel-based microgrippers were designed for surgical and soft robot applications using self-folding techniques [108]. Addition of magnetic nanoparticles to this composite system allowed remote actuation of these devices. In aqueous solutions at a temperature of $36^{\circ} \mathrm{C}$, the hydrogel-based system gives out water and contracts causing the microgripper to open and close itself in a particular direction. Similar actuation is achieved in the other direction by allowing the hydrogel to absorb water at a temp below $36^{\circ} \mathrm{C}$. Photolithography was employed to produce $3 \mathrm{D}$ structures with varying shapes and thickness from 2D poly (ethylene glycol) based hydrogels bilayers. These 2D bilayers folded to form the final shapes when exposed to thermal stimuli, thereby exhibiting the potential of active origami in the biomedical field [109]. Fig. 11 shows the self-folding displayed by these hydrogel bilayers.
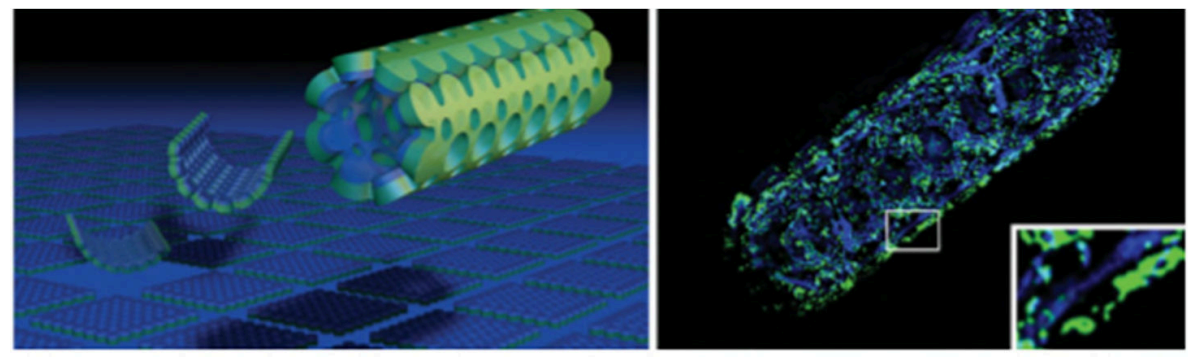

Fig. 11 Self-folding of PEG-based 3D hydrogel bilayers

(Reprinted with permission from [109], Copyright with License Number: 4630080589066)

\subsection{Stimuli based actuation}

The characteristic shape transformation exhibited by the 4D printed product is a response generated due to the effect of stimuli. These $4 \mathrm{D}$ printed products can contain a wide range of smart materials, each of which is actuated by different kinds of stimuli.

\subsubsection{Temperature-induced actuation}

Shape memory polymers can produce a change in their shape in response to fluctuation in thermal energy. SMPs have a transition temperature called the glass transition temp $\left(\mathrm{T}_{\mathrm{g}}\right)$ above which they get temporarily deformed. However, they can recover their original shape by means of a recovery force when reheated above $\mathrm{T}_{\mathrm{g}}$ [110]. A certain magnitude of internal stress is induced into SMPs during the printing process. These stresses are subsequently released when exposed to thermal stimuli. This phenomenon results in a microstructure transformation and the polymeric material is able to produce a change in its shape [111]. 


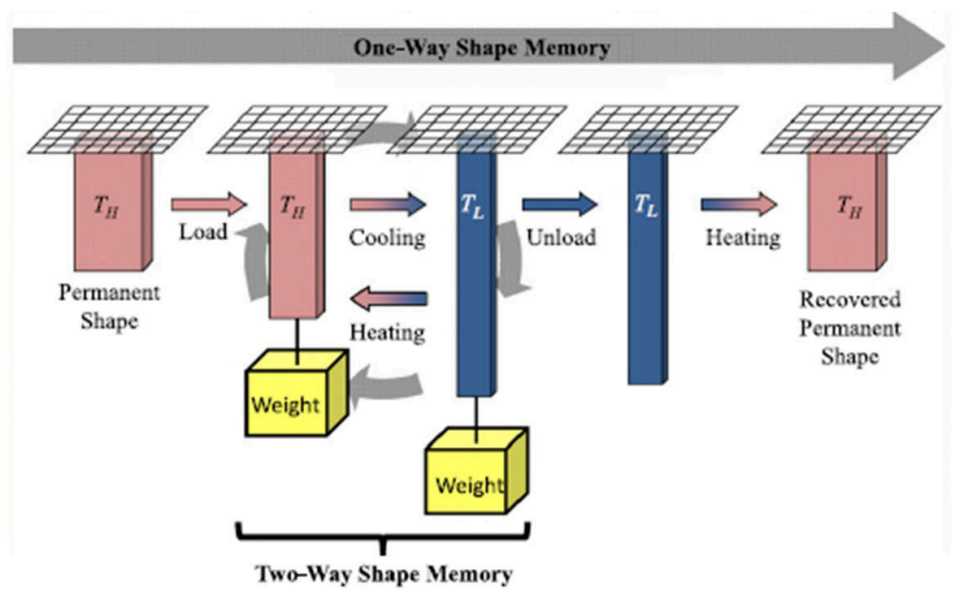

Fig. 12 One way and Two-way shape memory effect

(Reprinted with permission from [113], Copyright with License Number: 4621150956785)

Advancements in the study of thermal responsive SMPs have influenced the development of new and improved shape memory cycles, as presented by Fig. 12. Introduction of additional programming steps into the standard one-way shape memory effect $(1 \mathrm{~W}-1 \mathrm{SM})$ has led to the development of the two-way shape memory effect (2W-2SM). This $2 \mathrm{~W}-2 \mathrm{SM}$ is of great interest as it allows multiple memory shape cycles to take place [112]. Fig. 13 highlights one such multiple memory shape cycle.

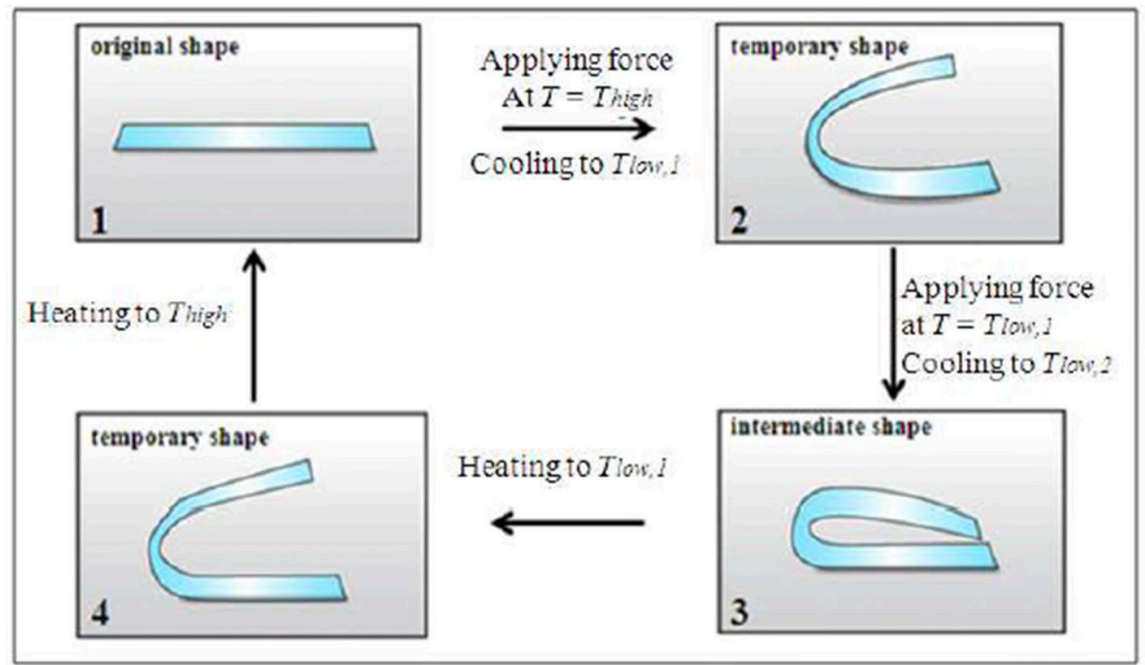

Fig. 14 Triple shape memory effect

(Reproduced from [112])

Several contraptions have since been developed which utilize these effects. A polymer actuator which utilizes the 2W-2SM has been designed to operate in the absence of any external load [113]. Research has also been oriented toward the development of thermo-responsive polymer laminates 
which follow 2W-2SM [114]. Crosslinked 2W-2SM polymers have also been used in the biomedical field for the construction of artificial muscles [115]. Studies have been conducted to make SMPs follow a certain shape-changing sequence when exposed to thermal stimuli. Samples of epoxy-based SMPs with varying compositions were printed to have different glass transition temperatures. This enabled these samples to follow a predetermined sequence to revert back to their original shape. This method was then applied for the creation of self interlocking and helical structures [116].

\subsubsection{Moisture or solvent-induced actuation}

Water or solvent-induced shape change in polyurethane SMPs is due to the plasticizing effect. Plasticizing makes the polymer more flexible and reduces the transition temperature to the ambient temperature of the solution [117]. The shape change mechanism triggers at the low transition temperature and consequently, the shape recovery process takes place. SMPs which produce shape change effect by exposure to water are generally created by the combination of hydrophobic and hydrophilic polymeric groups. The characteristics of one such group containing a hydrophilic polyurethane block copolymer and a hydrophobic polyhedral oligomeric silsesquioxane (POSS) were studied with the aim of generating different sets of properties by altering the ratios of these two components [118]. An increase in the POSS component caused an increase in the melting point and crystallinity of the material. Certain composite materials have shown significant shape change when magnetically actuated in a suitable solvent [119], as presented by Fig. 14. These highly flexible composites are ideal for the formation of highly biocompatible structures.

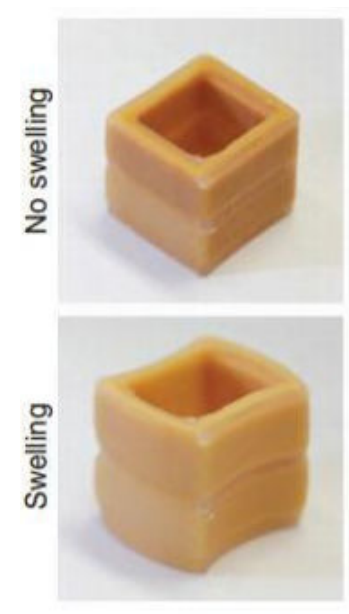

Fig. 14 Magnetically actuated material exhibiting shape change insolvent

\section{(Reproduced from open access [119])}

A variety of 3D shapes have been developed by immersing hydrogel comprising of cellulose fibers into water [120]. When exposed to water, these hydrogel-based materials expand anisotropically to form three dimensional shapes from simple sheets. However, the structures formed are found to be extremely weak and brittle. A 2D SU-8 film with a swellable guest medium was designed to form 3D structures in response to organic solvents [121]. These 3D structures could have a use in the field of bioelectronics (polymeric LEDs), regenerative medicine and soft robotics. 


\subsubsection{Magnetically induced actuation}

Shape memory nanocomposites containing magnetic nanoparticles like iron oxide $\left(\mathrm{Fe}_{3} \mathrm{O}_{4}\right)$ display shape-changing effects when exposed to alternating magnetic fields [122]. This particular property was utilized to manufacture scaffolds by $4 \mathrm{D}$ printing $\mathrm{Fe}_{3} \mathrm{O}_{4}$ based poly (lactic acid) based SMPs. These scaffolds expand in the presence of alternating magnetic fields and can potentially be employed as stents in the biomedical field. Similarly, the SMP system comprising of crosslinked poly(-caprolactone) and $\mathrm{Fe}_{3} \mathrm{O}_{4}$ nanoparticles can be utilized for formation of drug delivery systems and stents. The crosslinked polymer structures of these SMPs enable them to achieve a higher degree of shape recovery ratio [123]. Such electromagnetically induced shape change mechanism occurs due to properties of the super magnetic $\mathrm{Fe}_{3} \mathrm{O}_{4}$ particles. These particles cause inductive heating in the SMP, converting the energy from the external magnetic field into local heat energy which ultimately initiates the shape-changing process [124]. The use of electromagnetic induction for shape change allows the thermal energy required for the shape-changing mechanism to originate within the SMP itself.

Other applications of magnetically activated SMP include Nickel-zinc ferrite loaded SMP based medical devices which exhibit shape-changing effect when exposed to alternating magnetic fields [125]. Super magnetic nanocomposite based SMP systems has also been employed in the biomedical field. $8 \mathrm{wt} \%$ oleic acid-coated magnetic nanocomposite system exhibited shape memory effect when exposed to alternating magnetic fields [126].

\subsubsection{Light-induced actuation}

Light-induced activation is often considered to be a more favorable shape-changing initiator than thermal induced shape change. This is because light-activated SMPs can recover their shapes at ambient temp and thus do not require any external heat source [127].

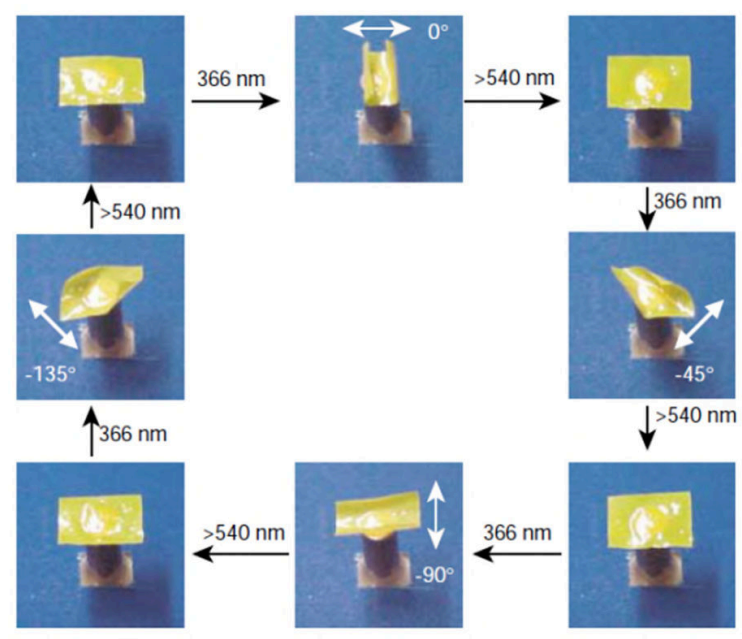

Fig. 15 Actuation of the smart polymer at different incidence angles and light wavelengths (Reprinted with permission from [129], Copyright with License Number: 4615890563585)

Photoinduced activation of crosslinked rubber polymeric material has been achieved by stress relaxation techniques [128]. Stress is induced on the crosslinked polymers by irradiating one side 
of the polymer. Upon relaxation, this stress dissipates within the material producing deformations and causing shape change. Azobenzene based liquid crystal polymeric networks exhibited shape change when exposed to linearly polarized light [129], as presented by Fig. 15. Changing the polarization of the incident light caused the material to bend in different directions. Azobenzene based liquid crystal polymers are also extensively used for light energy powered robotics applications [130]. Photoinduced actuation of robotics eliminates the need for additional mechanical components which are required in great numbers for traditional mechanical robotic systems. Polymers containing cinnamon groups were used to form a variety of complex shapes and structures by UV light activation [131]. These structures are not constrained like thermally induced SMPs and can recover their shape even at ambient temperature. Polymer gels having triphenylmethane leucocyanide groups swell in the water when exposed to ultraviolet radiation [132]. They de-swell when the radiation is removed. This swelling and deswelling cycle is attributed to the development of osmotic pressure between the polymeric gels and the water solution as a result of UV light exposure.

\section{Biomedical application}

SMPs have started to replace traditional polymers in the field of biomedical sciences. However, certain criteria for the design and selection of SMPs for biomedical applications should be followed [133]. Fig. 16 lists a few of these design parameters.

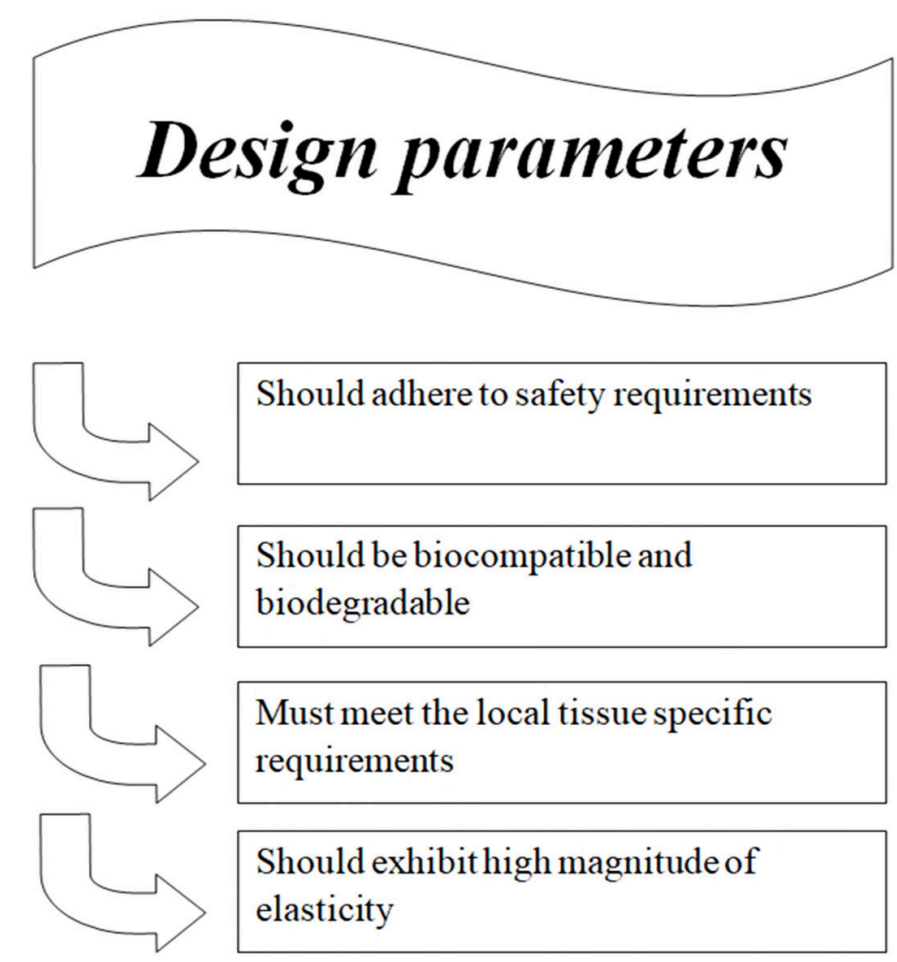

Fig. 16 Design parameters for biomedical smart devices

\subsection{Angiography}


Angiography is the medical procedure of introducing suitable materials into the arteries to locate blocked areas [134]. It involves introducing a medium into the arteries to locate blood clots or areas of blockage. This medium is fed through a catheter which is guided to its destination by guidewires. Guidewires composed of stainless steel was initially used for this process. However, these guidewires are prone to deformation and kinking as a result of which steering them inside the human body becomes difficult. Nitinol guidewires are now being extensively used for this purpose due to their high flexibility and good kink resistance [135]. This great elasticity and flexibility offered by Nitinol allow it to pass smoothly through various complex paths in blood vessels without deformation. Fig. 17 presents a nitinol based SMP used in the field of angiography

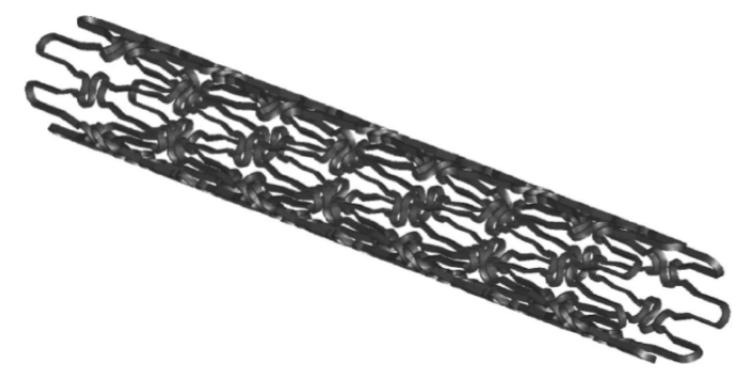

Fig. 17 Model of a nitinol-based stent employed for angiography

(Reprinted with permission from [135], Copyright with License Number: 4615890780880)

\subsection{Stents}

Angioplasty involves opening blocked blood vessels bypassing a stent along guidewires. This stent consists of a balloon which is expanded to provide an opening in the blood vessel. The superelasticity of nitinol makes it ideal for this operation [135].
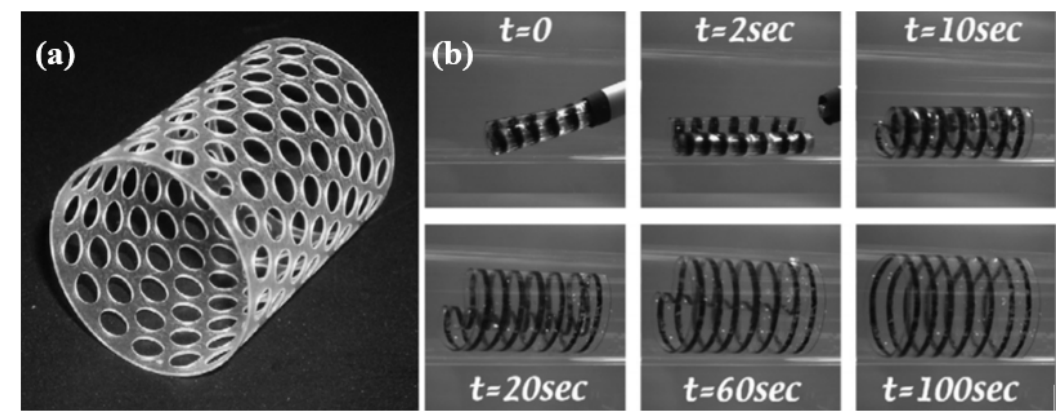

Fig. 18 (a) Perforated SMP stent (b) SMP stent-catheter system

\section{(Reprinted with permission from [138], Copyright with License Number: 4615891002938)}

For the proper functioning of a stent, it must provide just enough force to maintain the opening. If the force is too high, the stent will harm the adjacent vessels while if it is too low it would not be able to resist the forces of the adjacent vessels and the opening will close. Superelastic nitinol stents satisfy this stringent criterion. Nitinol exhibits high compatibility with the body and unlike stainless steel, it does not put a large amount of force on the blood vessels [136]. This biocompatibility of Nitinol is due to the formation of a passive titanium oxide layer which protects the material from corrosion and also makes it less prone to chemical breakdown [137]. Stents 
consisting of shape memory material coupled with a support structure have been designed as a non-invasive way of dealing with physical anomalies [138,139], as presented by Fig. 18. These devices are highly expandable and provide means of forming a variety of SMP foams with different structures and geometrical shapes. These foams expand into the physical anomaly to provide the necessary skeletal support.

\subsection{Drug release system}

SMPs can be used for storage and subsequent controlled release of drugs in biomedical application [140], as evidenced by Fig. 19. Oligo[( $\varepsilon$-caprolactone)-co-glycolide]-dimethacrylates based biodegradable drug delivery system has been successfully synthesized [141]. The shape memory process and the recovery mechanism of the drug delivery system were designed not to hamper the drug release capability of the material.

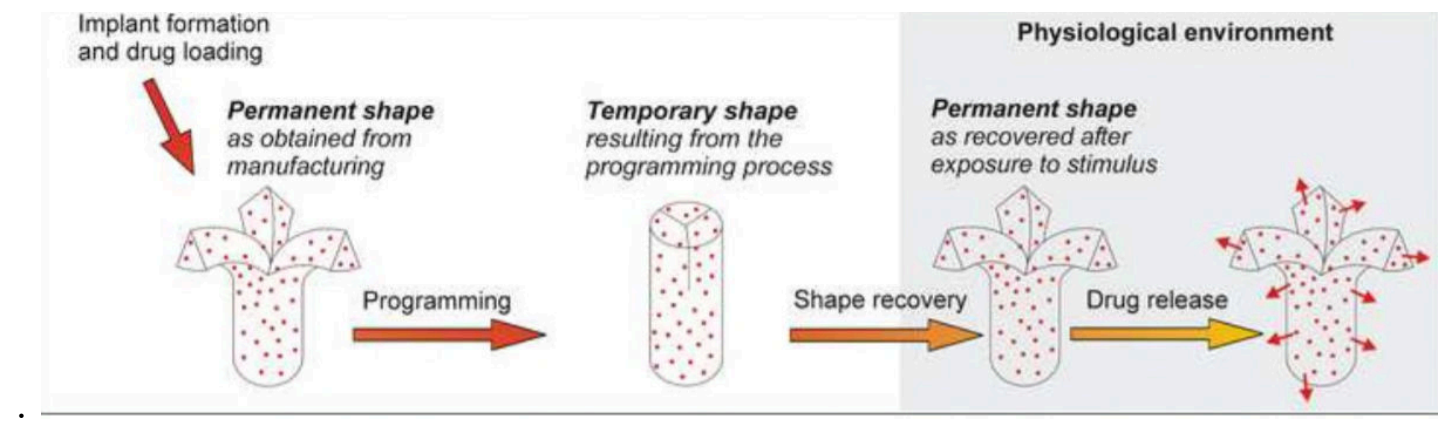

Fig. 19 The smart drug release system

(Reprinted with permission from [140], Copyright with License Number: 4615891281774)

\subsection{Artificial cornea implants}

Scaffolds developed from interpenetrating polymer networks (IPN) were used to make artificial cornea devices [142]. The use of IPNs allows the preparation of 3D scaffolds possessing high strength and high water retention capacity. These properties combined with their well defined highly porous structure leads to the development of extremely biocompatible devices, as shown in Fig. 20.

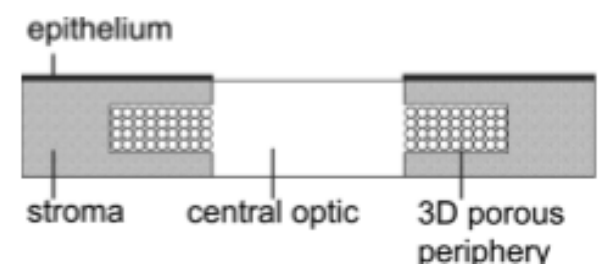

Fig. 20 IPN based artificial cornea cross-section

(Reprinted with permission from [142], Copyright with License Number: 4615891459124)

\subsection{Regenerative medicines and Tissue engineering}


Chitosan-based hydrogels have been used to manufacture wound dressing systems [143]. These systems employ rutin which significantly enhances the cellular healing process. Polypeptide hydrogels have been employed for the fabrication of wound healing systems [144]. These compounds possess antibacterial properties and exhibit a greater magnitude of cell proliferation which boosts the healing process. Scaffolds provide a base structure for molding of various polymeric biomaterial for tissue engineering. An ideal scaffold should have the required mechanical strength to support the cell and tissue constructs during their regeneration. The study by [145] provides an in-depth analysis of the various physical characteristics of biocompatible polymers used for the creation of scaffolds in tissue engineering.

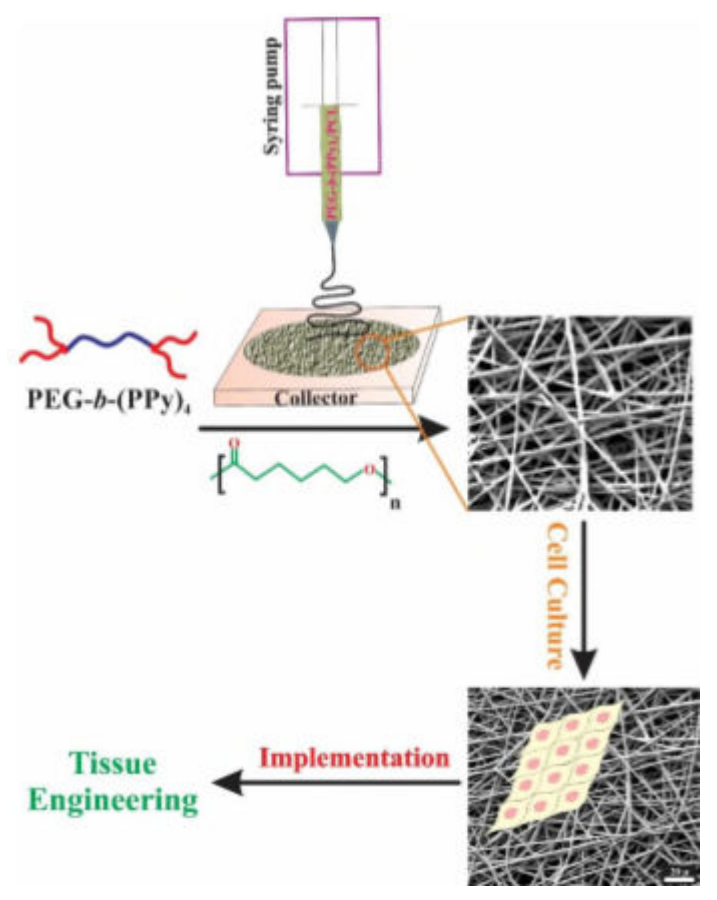

Fig. 21 Fabrication of nanofibrous scaffolds for tissue engineering

(Reprinted with permission from [146], Copyright with License Number: 4630110824863)

SMPs fabricated into ultrafine nanoscale fibers have been used to produce tissue engineering scaffolds [146,147], as shown in Fig. 21. These nanosized constructs combine the salubrious effect of both nanofibers and SMPs to form a system which is extremely biodegradable and highly efficient in bone and tissue recovery and repair. Nano-biocomposites of natural polymers can be used to design scaffolds for bone tissue engineering [148]. The scaffolds generated from a combination of natural polymers like chitosan, hydroxyapatite, gelatin and alginate provide good mechanical strength and help in cell proliferation. Table. 2 discusses some of the numerous other biomedical applications of smart materials. 


\begin{tabular}{|c|c|c|c|c|c|c|}
\hline \multirow[t]{2}{*}{ Field } & \multicolumn{2}{|c|}{ Printing Procedure } & \multirow[t]{2}{*}{ Materials } & \multirow[t]{2}{*}{ Advantages } & \multirow[t]{2}{*}{ Disadvantages } & \multirow[t]{2}{*}{ Reference } \\
\hline & Phenomena & Stimulus & & & & \\
\hline $\begin{array}{l}\text { Biomedical } \\
\text { polymeric } \\
\text { scaffolds }\end{array}$ & $\begin{array}{l}\text { Particulate } \\
\text { leaching }\end{array}$ & $\begin{array}{l}\text { Solvent } \\
\text { generated } \\
\text { response }\end{array}$ & $\begin{array}{l}\text { PLGA and } \\
\text { sodium chloride } \\
\text { in different } \\
\text { organic solvents }\end{array}$ & $\begin{array}{c}\text { Production of } \\
\text { highly porous } \\
\text { 3D scaffolds } \\
\text { without any } \\
\text { inherent } \\
\text { limitations }\end{array}$ & $\begin{array}{l}\text { Thermal } \\
\text { degradation of } \\
\text { the polymer } \\
\text { can occur } \\
\text { during the } \\
\text { process }\end{array}$ & $\begin{array}{l}\text { Liao et al. } \\
\text { [149] }\end{array}$ \\
\hline $\begin{array}{l}\text { SMP based } \\
\text { Thrombectomy } \\
\text { device }\end{array}$ & Laser heating & Heat & $\begin{array}{l}\text { MM6520 and } \\
\text { MM5520 } \\
\text { thermoplastic } \\
\text { SMPs }\end{array}$ & $\begin{array}{l}\text { Treatment of } \\
\text { ischemic stroke }\end{array}$ & $\begin{array}{l}\text { Modifications } \\
\text { are required } \\
\text { prior to in vivo } \\
\text { deployment }\end{array}$ & $\begin{array}{l}\text { Small IV et } \\
\text { al. } \\
{[150]}\end{array}$ \\
\hline $\begin{array}{c}\text { SMP } \\
\text { biocompatibility } \\
\text { study }\end{array}$ & $\begin{array}{l}\text { Laser or } \\
\text { electrical } \\
\text { heating }\end{array}$ & Heat & $\begin{array}{l}\text { MP-5510 } \\
\text { thermoset resin } \\
\text { and MM-5520 } \\
\text { thermoplastic } \\
\text { resin }\end{array}$ & $\begin{array}{l}\text { SMP specimens } \\
\text { ideal candidates } \\
\text { for vascular } \\
\text { stents }\end{array}$ & $\begin{array}{c}\text { SMP } \\
\text { specimens } \\
\text { don't enhance } \\
\text { platelet } \\
\text { activation } \\
\text { under shear } \\
\text { conditions }\end{array}$ & $\begin{array}{c}\text { Cabanlit et } \\
\text { al. } \\
{[151]}\end{array}$ \\
\hline $\begin{array}{c}\text { Tissue } \\
\text { Engineering }\end{array}$ & \multicolumn{2}{|c|}{$\begin{array}{l}\text { Custom multi-material 3D printing } \\
\text { with varying Pressure, 3D printer } \\
\text { speed and nozzle height }\end{array}$} & $\begin{array}{l}\text { Three primary } \\
\text { inks used with the } \\
\text { following } \\
\text { composition: A } \\
\text { 10:1 base to } \\
\text { catalyst silicone } \\
\text { elastomer, } 40 \mathrm{wt} \\
\% \text { Pluronic F127 } \\
\text { in DIUF water, } \\
\text { GelMA solution }\end{array}$ & $\begin{array}{l}\text { Construction of } \\
\text { highly complex } \\
\text { multi-material } \\
\text { tissue constructs }\end{array}$ & $\begin{array}{l}\text { Factors like } \\
\text { pressure, } \\
\text { nozzle } \\
\text { diameter, } \\
\text { engineering } \\
\text { environment } \\
\text { and build time } \\
\text { have to studied } \\
\text { separately for } \\
\text { optimization }\end{array}$ & $\begin{array}{c}\text { Kolesky et } \\
\text { al. } \\
{[152]}\end{array}$ \\
\hline $\begin{array}{l}\text { Vascular } \\
\text { phantom } \\
\text { fabrication }\end{array}$ & \multicolumn{2}{|c|}{ Polyjet 3D printing } & $\begin{array}{c}\text { Combination of } \\
\text { three materials. } \\
\text { The primary one } \\
\text { is a hard material } \\
\text { while the } \\
\text { secondary is a soft } \\
\text { elastic material. } \\
\text { Additional } \\
\text { support material } \\
\text { is also added. }\end{array}$ & $\begin{array}{c}\text { Geometrical } \\
\text { accuracy and } \\
\text { mechanical } \\
\text { evaluation }\end{array}$ & $\begin{array}{l}\text { Non-optimal } \\
\text { STL file design } \\
\text { and the pre and } \\
\text { post-print } \\
\text { workflow } \\
\text { phase }\end{array}$ & $\begin{array}{c}\text { Ionita et al. } \\
{[153]}\end{array}$ \\
\hline $\begin{array}{l}\text { Biomedical } \\
\text { microbots }\end{array}$ & $\begin{array}{l}\text { Expansion of } \\
\text { different layers }\end{array}$ & $\begin{array}{l}\text { Heat and water } \\
\text { generated a } \\
\text { response }\end{array}$ & $\begin{array}{l}\text { A hydrogel } \\
\text { comprising } \\
\text { NIPAAm, } \\
\text { acrylamide and } \\
\text { PEGDA }\end{array}$ & $\begin{array}{l}\text { Extremely } \\
\text { versatile and } \\
\text { feature-rich } \\
\text { prototype } \\
\text { microbot }\end{array}$ & $\begin{array}{l}\text { Further } \\
\text { optimization of } \\
\text { the microbot } \\
\text { requires } \\
\text { extensive } \\
\text { studies of its } \\
\text { physical design }\end{array}$ & $\begin{array}{c}\text { Fusco et al. } \\
{[154]}\end{array}$ \\
\hline
\end{tabular}




\begin{tabular}{c|c|c|c|c|c|}
$\begin{array}{c}\text { Tissue } \\
\text { Engineering }\end{array}$ & $\begin{array}{c}\text { 3D Printing using Novogen MMX } \\
\text { bioprinter }\end{array}$ & $\begin{array}{c}\text { A solution of } \\
\text { Novogel and PBS } \\
\text { (phosphate } \\
\text { buffered saline) }\end{array}$ & $\begin{array}{c}\text { The printing } \\
\text { strategies } \\
\text { employed are } \\
\text { conducive to } \\
\text { cell fusion }\end{array}$ & $\begin{array}{c}\text { The maximum } \\
\text { length of } \\
\text { extruded } \\
\text { material } \\
\text { is limited. }\end{array}$ & $\begin{array}{c}\text { Kucukgul et } \\
\text { al. }\end{array}$ \\
\hline
\end{tabular}

Table. 2 Biomedical applications of smart materials

\section{Engineering and Structural Applications}

\subsection{Aerospace and Aeronautical industry}

Significant endeavors have been undertaken to incorporate active materials such as SMAs and SMPs into aerospace technologies. A significant amount of research has been oriented towards utilization of SMPs to form space inflatable systems such as SMP foam-based antennas [156]. Spacecraft which employ SMP based deployment mechanism has also been developed. This design consists of a shape memory actuator which launches the deployment mechanism based on the response from a heat source [157]. Usage of SMPs for this design enables spacecraft to occupy a smaller volume. Smart memory materials are also being considered for use in deployable secondary structures for planetary exploration and settlement [158,159]. Fig. 22 displays one such aerospace application of SMPs.

The cold hibernated elastic memory (CHEM) technology employs SMPs to form self deployable, highly flexible, low-cost structures [160]. The material is made flexible by heating it above its glass transition temp $\left(\mathrm{T}_{\mathrm{g}}\right)$. After achieving the required shape, it has to be cooled below $\mathrm{T}_{\mathrm{g}}$ to become solidified. This technology offers several advantages over traditional space deployment structures. It simplifies the deployment mechanism and occupies a very small amount of space. It also has excellent damping capability which makes it ideal for tolerating debris impact in space [161].
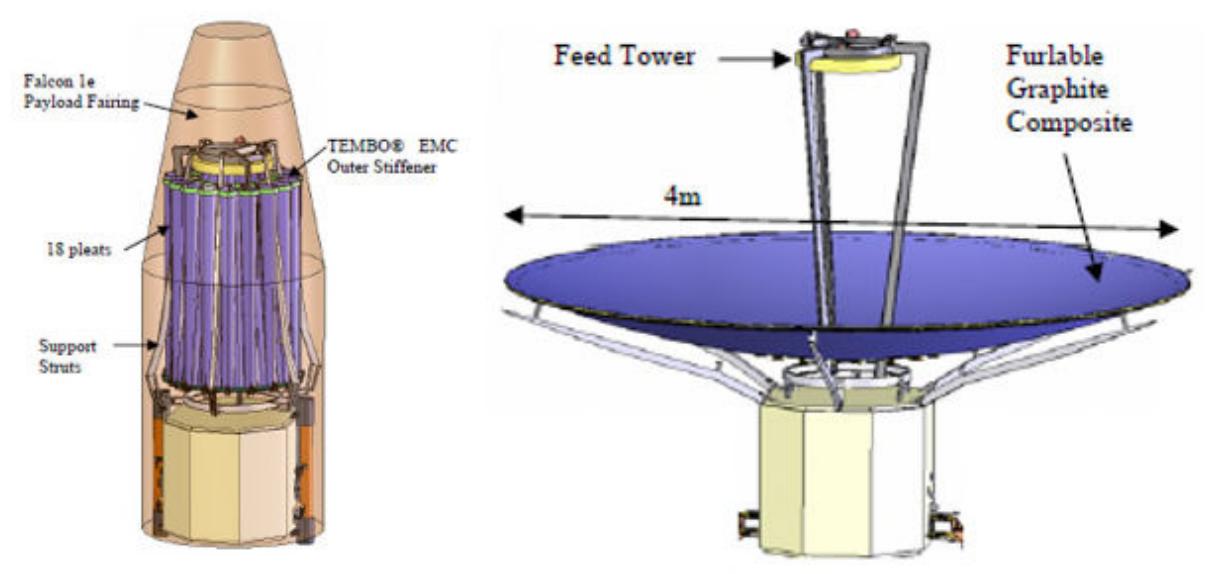

Fig. 22 Aerospace application of SMPs as a Solid Surface Reflector (Reproduced from [159]) 
SMPs have also been used in aeronautical industries for the production of tradition aircraft components. Deployable wings manufactured from SMPs offer considerable advantages over traditional mechanical deployment technology [162]. These SMP based technologies provide a low-cost alternative to traditional technology with the added benefit of occupying a smaller storage volume. Incorporation of this technology has also led to less reliance on mechanical components such as hinges and servos. These systems have also been proved to maintain the correct aerodynamic configuration by performing thorough static deformation analysis.

Several aerodynamical projects like the DARPA smart wing program have been designed to utilize the shape memory effect of active materials. These projects aimed to incorporate active materials like SMAs into traditional aircraft to enhance their aerodynamic performance [163]. SMAs have also been incorporated in composites to develop extremely tough and ductile structures. These structures can absorb a large magnitude of energy before failure which along with their other salubrious properties makes them ideal for aeronautical applications [164]. SMAs can be employed in the field of adaptive aerodynamics to develop vehicles with optimum aerodynamic configuration. Vehicular components like spoilers and rear upper panels designed from SMAs can significantly improve the aerodynamical performance of vehicles [165].

SMAs can also be utilized to achieve precise actuation in space antennas [166]. SMAs provide an ideal replacement for traditional actuation systems which have a very limited life span. SMAs do not require lubricants and are considerably inexpensive as they do not require supplementary mechanical components like gears and motors. Elastic memory composite (EMC) hinges fabricated from graphite sheets and EMC resins serve as inexpensive and reliable means of deployment in spacecraft, satellites and solar panels [167].

\subsection{Soft Robotics and Shape memory actuators}

The exponentially growing field of Soft Robotics pertains to the development of robots made from soft and highly stretchable materials. These robots are highly flexible and capable of achieving executing complex motions with great maneuverability [168]. 4D printing techniques have been used to print inks comprising of crosslinked liquid crystalline polymers and photoinitiators [169]. When exposed to suitable thermal stimuli, these inks can generate complex actuators which have application in soft robotics.

A soft robotic arm inspired from the muscular hydrostat of an octopus has been designed to successfully emulate the movements of an octopus's arm. This robotic structure comprises of smart actuators and a sleeve support structure which allows the robotic arm to bend in all directions [170]. The origami uni-bot is a soft robot exhibiting reversible actuation. This robot can potentially be employed in the biomedical industry as drug delivery system due to its dual shape memory behavior [171]. Environment-friendly soft robots have been designed for non-destructive sampling of deep coral reefs. These soft robots are highly compatible with the natural coral reef system and thus can safely handle the specimens [172]. SMP based triboelectric nanogenerator (STENG) has been developed which can act as biosensor and energy harvester. This highly stretchable sensor harvests mechanical energy to shape change when activated by the thermal stimulus. This STENG is highly stretchable and can easily adapt to different surface topographies, as shown by Fig. 23. It 
can potentially be employed as a wrist splint which can alter its shape by thermal activation. Further, its ability to recover its original shape makes it ideal for soft robotic applications [173].

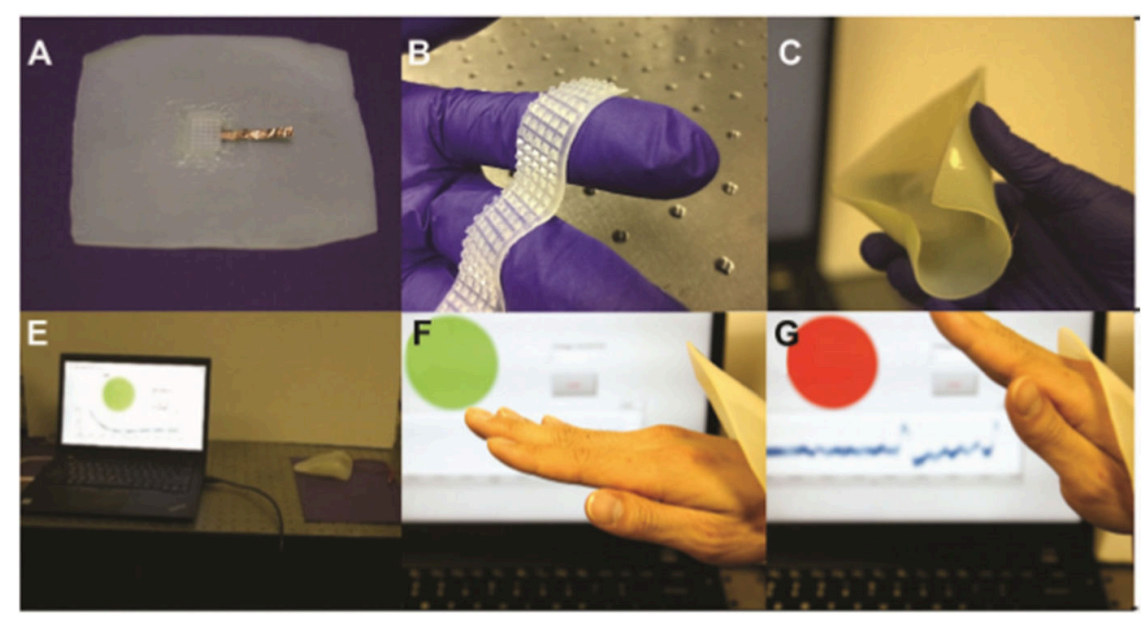

Fig. 23 STENG shape-changing wrist splint

\section{(Reprinted with permission from [173], Copyright with License Number: 4630111089845)}

Several studies have been dedicated to designing shape memory material based soft robotic grippers [174-178]. These grippers are extremely agile and capable of handling a large selection of objects. Fig. 24 and Fig. 25 provide examples of soft robotic systems which are designed to perform unique tasks.

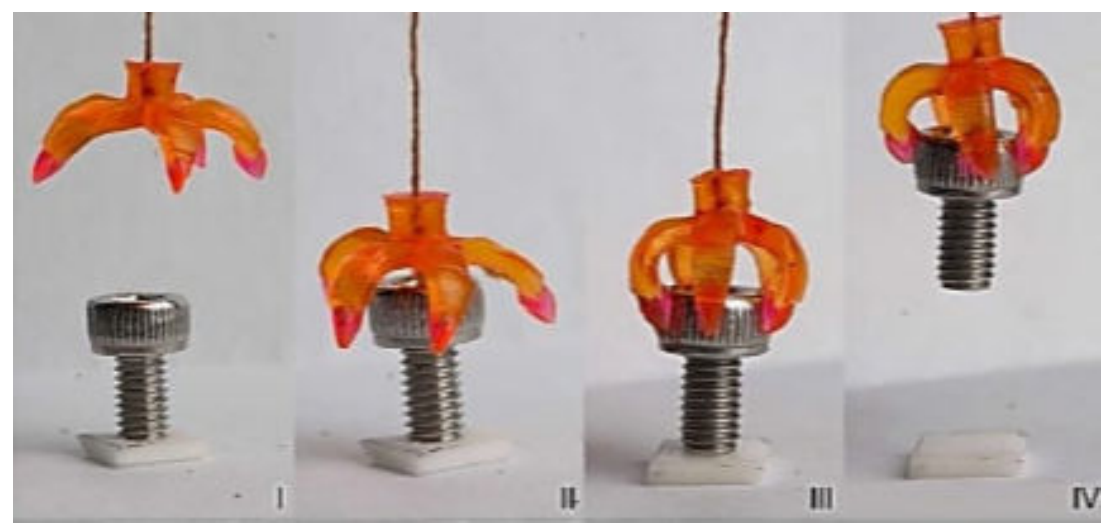

Fig. 24 Heat actuated soft robotic grippers

\section{(Reproduced from [99])}

Significant research has been done on SMP based actuators which can respond to different stimuli. Use of these actuators simplifies the process by removal of all unnecessary mechanical and electrical parts. The SMP based actuators designed by [179] comprise of a shape memory member, a deformable part and a retaining element. When the shape memory member is activated, the deformable member deforms as a consequence of which the retaining element generates a mechanical motion. These actuators can then be implemented in release mechanisms which are 
commonly employed in space, aeronautical and transportation sectors. SMA based actuators have also been developed. SMA based actuators which can provide a great degree of the movement have found their application in wearable robotics [180].

Development in the field of soft robotics would allow the replacement of stiff robotic structures with highly responsive smart components. Soft robotic components are able to perform a larger range of operations due to their high flexibility. New and more efficient modeling and printing techniques have to be designed to spread the influence of soft robotics in the current industrial sector. Further evolution of soft robotics can see them integrating with artificial intelligence and machine learning to form highly flexible self-learning robotic units.
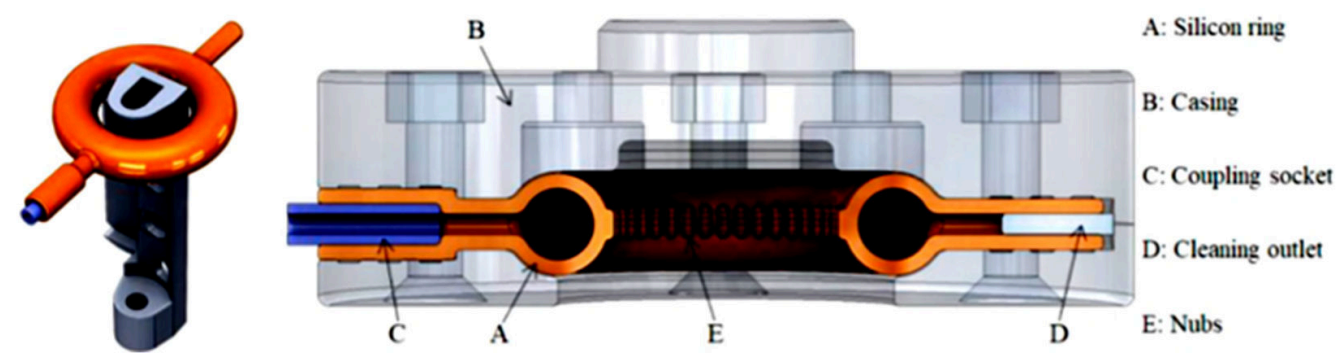

Fig. 25 Soft Robotic ring gripper

(Reprinted with permission from [178], Copyright with License Number: 4630111309171)

\subsection{Additional Structural and mechanical applications}

Paper is an environmentally friendly, cost-effective and low weight material which makes it ideal for prototyping applications. 3D printed papercrafts integrated with electronics were designed using a novel strategy named Printed Electronic papercrafts (PEP) [181]. The strategy highlights a seven-step process for printing electronic papercrafts which can then be used for several applications. These include the creation of detailed architectural prototypes, water sensing flowerpots, smart toys and electroluminescent photo frames. Structures designed from pneumatically actuated soft composites can be used to create shape-changing prototypes of mobiles, tablet cases and lamps [182]. Composite structures used for the design process have a complex multilayer geometry comprising of two structural layers, a sensing layer and an additional add-on layer. The two structural layers are required to generate both isotropic and anisotropic deformation. The sensing layer has conductive material for sensing input and output while the addon layer influences the material properties of the structure. Polyurethane based SMPs have been utilized to create I beam shaped fasteners for the assembly of microbots [183]. Traditionally the assembling process is done with the aid of adhesives, however, the demand for new and more complex microbots have rendered adhesives anachronistic. These SMPs offer several basic advantages over adhesives. They can be easily removed by exposure to heat, can prevent stress concentration and are easily replaced which makes the repairing process for microbots considerably easier. Table. 3 provides insight into other important applications of smart materials. The advances in technologies like PEP can help the industry to arrive at a more environmental friendly and sustainable future. The primary advantage of these techniques is their use of universally available material which opens up this research field to a larger audience leading to more innovation. Development of new 3D printers which are compatible with highly elastic base 
material can enhance the entire fabrication process of soft composite based shape-changing structures. This can potentially be used to generate more dynamic devices capable of assuming multiple shapes. 
Table. 3 Structural and engineering applications of smart materials (Images reproduced from $[159,184,186,187,189]$

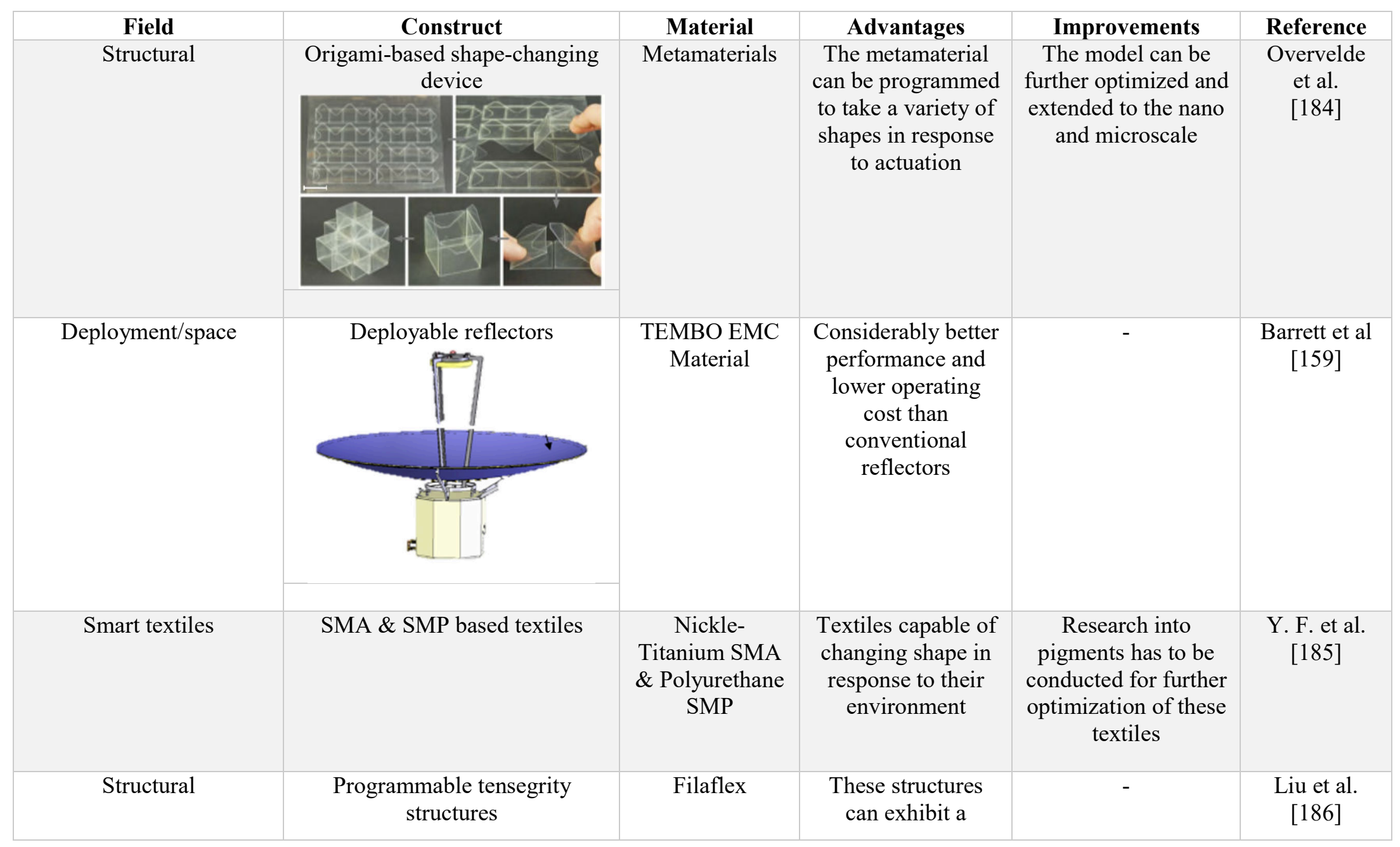




\begin{tabular}{|c|c|c|c|c|c|}
\hline & 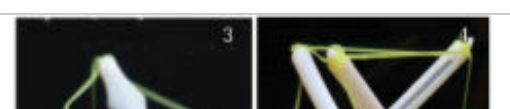 & & $\begin{array}{l}\text { gigantic magnitude } \\
\text { of shape change }\end{array}$ & & \\
\hline Transportation/packaging & Shape changing actuator & $\begin{array}{l}\text { Polyurethane } \\
\text { shape-memory } \\
\text { polymer }\end{array}$ & $\begin{array}{l}\text { The proposed } \\
\text { structure can form } \\
\text { various shapes } \\
\text { making it ideal for } \\
\text { transportation } \\
\text { purpose }\end{array}$ & - & $\begin{array}{l}\text { Beites } \\
{[187]}\end{array}$ \\
\hline Deployment/space & Deployable hinge & $\begin{array}{l}\text { Fiber-reinforced } \\
\text { thermoset } \\
\text { styrene-based } \\
\text { shape-memory } \\
\text { polymer } \\
\text { composite } \\
\text { (SMPC) }\end{array}$ & $\begin{array}{c}\text { Has a greater } \\
\text { storage modulus } \\
\text { than those of } \\
\text { conventional SMPs }\end{array}$ & $\begin{array}{l}\text { Delamination and } \\
\text { buckling of SMPs } \\
\text { have to be } \\
\text { considered for } \\
\text { optimization }\end{array}$ & $\begin{array}{l}\text { Lan et al. } \\
\text { [188] }\end{array}$ \\
\hline Aeronautical & SMP based slat-cove filler & $\begin{array}{l}\text { Shape memory } \\
\text { polymer } \\
\text { composites } \\
\text { (LaRC-SMPC) }\end{array}$ & $\begin{array}{l}\text { Biocompatible } \\
\text { biodegradable, } \\
\text { ductile and light }\end{array}$ & $\begin{array}{l}\text { Investigation under } \\
\text { simulated } \\
\text { aerodynamic load } \\
\text { exposed } \\
\text { shortcomings in the } \\
\text { material }\end{array}$ & $\begin{array}{c}\text { Kang et al. } \\
\text { [189] }\end{array}$ \\
\hline Deployment/space & Deployable Tensegrity reflectors & PETG & $\begin{array}{l}\text { Reduction of } \\
\text { mechanical } \\
\text { components and the } \\
\text { net cost of the } \\
\text { structure }\end{array}$ & $\begin{array}{l}\text { Issues concerning } \\
\text { reflector deployment } \\
\text { sequence have to } \\
\text { resolve for } \\
\text { optimization }\end{array}$ & $\begin{array}{c}\text { Tibert et al } \\
{[190]}\end{array}$ \\
\hline
\end{tabular}




\section{Avenues for Future research}

The numerous advances in 4D printing offer an exciting future wherein the technique would be used across all the different industrial and manufacturing sectors. For the accomplishment of this future, there is a need to develop new and highly customizable material which could respond to a range of external stimuli to undergo their respective shape transformation. There is a need to develop new 4D printing software for the different types of 4D printing techniques. Software development has to take into consideration the base smart material, the printing technique, geometrical and structural requirements of the final product and the shape-changing mechanism of the $4 \mathrm{D}$ printing technique. 4D printing techniques have to be developed which can adapt to different materials and are not throttled to a single material. 4D printing has great potential in the many subfields of biomedical engineering. However, significant efforts have to be made to develop faster, more cost-effective bioprinting techniques.

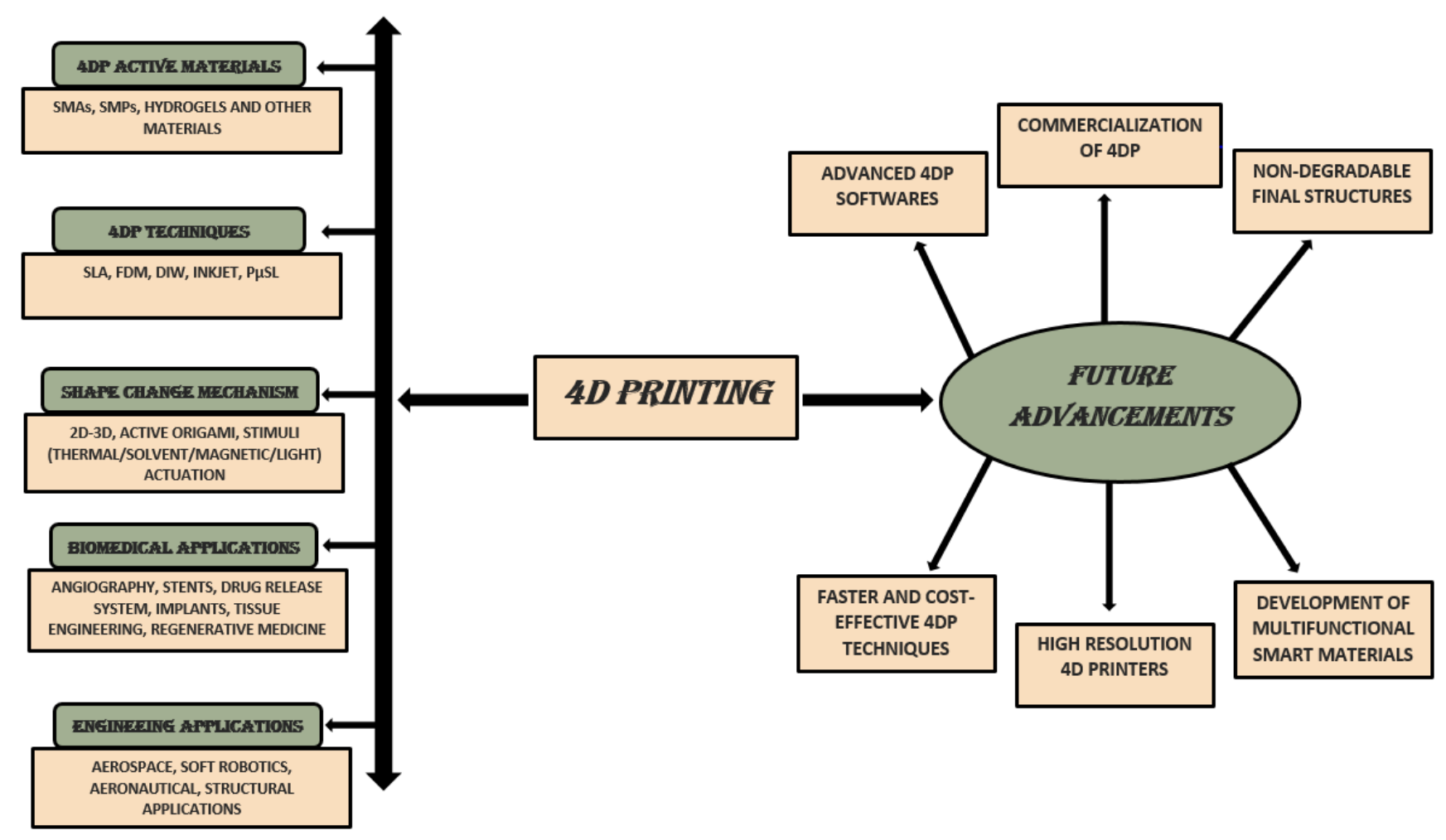

Fig. 26 Summary of the review and the future advancements for 4D printing

There is a need to develop biocompatible smart materials which do not have limited compatibility and can provide full functionality with multiple tissue and stimuli system [191]. The next iteration of smart biomedical devices should be able to undergo complex movements, enabling them to work more effectively inside the human body. Research has to be oriented toward reducing the development times of new biopolymers. Multifunctional materials that are capable of providing numerous functions singlehandedly have to be adapted thoroughly for the fabrication of biomedical devices [192]. It is essential to develop high resolution fully automated bioprinters which are affordable, user-friendly and commercially viable [193]. 4D printing has to be expanded beyond its 
current application to utilize its far-reaching scope. There is a need for the development of new smart materials which can be employed for novel shape programming techniques. Research has to be conducted to enable the generation of more complex structures and to diversify the existing roster of base smart materials for 4D printing processes. Another important area of research on 4D printing is the degradability of the final structures. Structures capable of changing shape over time are prone to degenerate and thus significant research has to be done to make this shape changing process repeatable and more feasible in the long term. Fig. 26 provides a succinct summary and highlights the different issues and topics discussed in this review.

Apart from the various applications discussed earlier, 4D printed products find potential
applications in human body systems such as artificial muscles, implantable biomedical
microdevices and wearable sensors. The use of this technology through printed enzymes can impact
tissue engineering such as vascularization and tissue production. 4D printed self deformed
microcapsules can be one of the future products which cover the wounds and prevent further
corrosion by gastric acid. This technology can find huge application in printing customized contact
lenses, and personal hygiene products. Other practical applications and sub-products include
deployable aerospace structures such as morphing aircraft wing, reconfigurable, functionally
deployable and mechanically tunable structures and shape-changing photovoltaic Fsolar cells.
Interestingly 4D printing has also found its potential use in fabricating dynamic jewelry such as
Responsive rings that change color with temperature and footwear accessories such as shoe with
Smart Heel. 4D printing technology is in the initial phase of commercialization. This reflects the
high cost to throughput ratio. This emerging technology helps in enhancing the sustainable
environment by minimizing the wastage of natural resources thereby reducing the cost in the long
run and provide sustainable alternatives to existing products. 4D printing market is set to witness a
series of new eco-friendly product launches and partnerships across the value chain resulting in
resource efficiency and sustainable consumption.

\section{Conclusions}

Since its inception, 4D printing has grown considerably and has spread its influence in numerous industrial sectors. 4D printing generally employs 3D printing technology with smart material to generate a shape change mechanism with time. This provides great flexibility and versatility as one final structure can potentially serve multiple functions.

The future with 4D printed materials is bright and highly optimistic. 4D printing has the potential to eliminate the inherent weakness of mechanical systems. 4D printed smart materials can be used to design novel systems which are not limited to any particular degree of freedom. This can be achieved by replacing traditional mechanical components like motor and gears with appropriate smart materials. New and more efficient methods of incorporating electronics into smart structures can lead to the development of the novel smart device. Development of biocompatible smart material systems can revolutionize the medical sector and can boost the efficiency of the healing process. It is very difficult to imagine a future where $4 \mathrm{D}$ printing does not have a significant impact on the industrial sector.

\section{Acknowledgment}


The authors are most thankful to the Department of Science \& Technology and UK-India Education and Research Initiative (DST-UKIERI) for providing the necessary monetary aid for the fruition of this study (DST/INT/UK/P-164/2017)

\section{References}

[1] K. V Wong, A. Hernandez, A Review of Additive Manufacturing, ISRN Mech. Eng. 2012 (2012). doi:10.5402/2012/208760.

[2] W. Gao, Y. Zhang, D. Ramanujan, K. Ramani, Y. Chen, C.B. Williams, C.C.L. Wang, Y.C. Shin, S. Zhang, P.D. Zavattieri, Computer-Aided Design The status, challenges, and future of additive manufacturing in, Comput. Des. (2015). doi:10.1016/j.cad.2015.04.001.

[3] D.J. Ravnic, A.N. Leberfinger, S. V. Koduru, M. Hospodiuk, K.K. Moncal, P. Datta, M. Dey, E. Rizk, I.T. Ozbolat, Transplantation of Bioprinted Tissues and Organs, Ann. Surg. 266 (2017) 48-58. doi:10.1097/SLA.0000000000002141.

[4] H. Kang, S.J. Lee, I.K. Ko, C. Kengla, J.J. Yoo, A. Atala, A 3D bioprinting system to produce human-scale tissue constructs with structural integrity, Nat. Biotechnol. 34 (2016) 312-319. doi:10.1038/nbt.3413.

[5] S. Patra, V. Young, A Review of 3D Printing Techniques and the Future in Biofabrication of Bioprinted Tissue, Cell Biochem. Biophys. 74 (2016) 93-98. doi:10.1007/s12013-016-07300 .

[6] V.K. Lee, A. Dias, M.S. Ozturk, K. Chen, B. Tricomi, D.T. Corr, X. Intes, G. Dai, Bioprinting in Regenerative Medicine, Springer International Publishing, Cham, 2015. doi:10.1007/9783-319-21386-6.

[7] N. Oxman, Variable property rapid prototyping, Virtual Phys. Prototyp. 6 (2011) 37-41. doi:10.1080/17452759.2011.558588.

[8] S. Tibbits, C. McKnelly, C. Olguin, D. Dikovsky, S. Hirsch, 4D Printing and universal transformation, (2013) 539-548.

[9] D. Gurung, Technological comparison of 3D and 4D printing, Arcada University of Applied Sciences, 2017.

[10] S. Tibbits, Design to, Spec. IssueMaterial Comput. High. Integr. Morphog. Des. 82 (2012) $68-73$.

[11] E. Pei, 4D Printing : dawn of an emerging technology cycle, Assem. Autom. 34 (2014) 2-7. doi:10.1108/AA-07-2014-062.

[12] Grand View Research, 4D Printing Market Analysis By Material ( Programmable Carbon Fiber, Programmable Wood, Programmable Textiles ), By End-use ( Defense, Aerospace, Automotive, Textile, Healthcare ), By Region, And Segment Forecasts , 2019 - 2025, 2017.

[13] Z.X. Khoo, J.E.M. Teoh, Y. Liu, C.K. Chua, J. An, K.F. Leong, W.Y. Yeong, 3D printing of smart materials: A review on recent progresses in 4D printing, Virtual Phys. Prototyp. 10 (2015). doi:10.1080/17452759.2015.1097054.

[14] S. Ramesh, C. Usha, N.K. Naulakha, C.R. Adithyakumar, M.L.K. Reddy, Advancements in 
the Research of 4D Printing-A Review ADVANCEMENTS IN THE RESEARCH OF 4D PRINTING-A REVIEW, IOP Conf. Ser. Mater. Sci. Eng. 376 (2018). doi:10.1088/1757899X/376/1/012123.

[15] K. Yu, A. Ritchie, Y. Mao, M.L. Dunn, H.J. Qi, Controlled Sequential Shape Changing Components by 3D Printing of Shape Memory Polymer Multimaterials, Procedia IUTAM. 12 (2015) 193-203. doi:10.1016/j.piutam.2014.12.021.

[16] J. An, C.K. Chua, V. Mironov, A perspective on 4D bioprinting, Int. J. Bioprinting. 2 (2016) $3-5$.

[17] G. Sossou, F. Demoly, G. Montavon, S. Gomes, TOWARDS A TOP-DOWN DESIGN METHODOLOGY FOR 4D, in: DS 87-5 Proc. 21st Int. Conf. Eng. Des. (ICED 17) Vol 5 Des. X, Des. to X, Vancouver, 2017: pp. 395-404.

[18] L. Yao, J. Ou, C. Cheng, H. Steiner, W. Wang, G. Wang, H. Ishii, bioLogic : Natto Cells as Nano actuators for Shape Changing Interfaces, in: Proc. 33rd Annu. ACM Conf. Hum. Factors Comput. Syst. ACM, Seoul, Korea, 2015: pp. 1-10. doi:10.1145/2702123.2702611.

[19] G. Wang, L. Yao, W. Wang, J. Ou, C. Cheng, H. Ishii, xPrint : A Modularized Liquid Printer for Smart Materials Deposition, in: Proc. 2016 CHI Conf. Hum. Factors Comput. Syst., ACM, San Jose, CA, USA, 2016: pp. 5743-5752. doi:10.1145/2858036.2858281.

[20] S.K. Leist, J. Zhou, Current status of 4D printing technology and the potential of lightreactive smart materials as $4 \mathrm{D}$ printable materials materials as $4 \mathrm{D}$ printable materials, Virtual Phys. Prototyp. 11 (2016) 249-262. doi:10.1080/17452759.2016.1198630.

[21] S. Chung, S.E. Song, Y.T. Cho, Effective Software Solutions for 4D Printing: A Review and Proposal, Int. J. Precis. Eng. Manuf. Technol. 4 (2017) 359-371. doi:10.1007/s40684-0170041-y.

[22] P.M. Cipollo, B.S. Surrusco, An Electrically Actuated Pin-Puller for Space Application using Nickel-Titanium Memory Alloy, (2004).

[23] G.Z. Wang, Effect of martensite transformation on fracture behavior of shape memory alloy NiTi in a notched specimen, Int. J. Fract. 146 (2007) 93-104. doi:10.1007/s10704-007-91484.

[24] S. Yi, S. Gao, Fracture toughening mechanism of shape memory alloys due to martensite transformation, Int. J. Solids Struct. 37 (2000) 5315-5327. doi:https://doi.org/10.1016/S0020-7683(99)00213-9.

[25] W. Yan, C.H. Wang, X.P. Zhang, Y.-W. Mai, Effect of transformation volume contraction on the toughness of superelastic shape memory alloys, Smart Mater. Struct. 11 (2002). https://iopscience.iop.org/article/10.1088/0964-1726/11/6/316/pdf.

[26] C.S. Loh, H. Yokoi, T. Arai, New Shape Memory Alloy Actuator : Design and Application in the Prosthetic Hand, in: 2005 IEEE Eng. Med. Biol. 27th Annu. Conf., IEEE, Shanghai, China, 2005: pp. 6900-6903. doi:10.1109/IEMBS.2005.1616092.

[27] Y. Haga, Y. Tanahashi, M. Esashi, Small diameter active catheter using shape memory alloy, in: Proc. MEMS 98. IEEE. Elev. Annu. Int. Work. Micro Electro Mech. Syst. An Investig. Micro Struct. Sensors, Actuators, Mach. Syst. (Cat. No.98CH36176), IEEE, Heidelberg, 
Germany, 1998: pp. 419-424. doi:10.1109/MEMSYS.1998.659793.

[28] A. Cladera, B. Weber, C. Leinenbach, C. Czaderski, M. Shahverdi, M. Motavalli, Iron-based shape memory alloys for civil engineering structures : An overview, Constr. Build. Mater. 63 (2014) 281-293. doi:10.1016/j.conbuildmat.2014.04.032.

[29] S.M. Saghaian, H.E. Karaca, M. Souri, A.S. Turabi, R.D. Noebe, Tensile shape memory behavior of Ni50.3Ti29.7Hf20 high temperature shape memory alloys, Mater. Des. 101 (2016) 340-345. doi:10.1016/j.matdes.2016.03.163.

[30] R.Y. Umetsu, X. Xu, R. Kainuma, NiMn-based metamagnetic shape memory alloys, Scr. Mater. 116 (2016) 1-6. doi:10.1016/j.scriptamat.2016.01.006.

[31] J. Mohd, M. Leary, A. Subic, M.A. Gibson, A review of shape memory alloy research , applications and opportunities, Mater. Des. $56 \quad$ (2014) 1078-1113. doi:10.1016/j.matdes.2013.11.084.

[32] P. Thamburaja, H. Pan, F.S. Chau, Martensitic reorientation and shape-memory effect in initially textured polycrystalline $\mathrm{Ti}$ - Ni sheet, Acta Mater. 53 (2005) 3821-3831. doi:10.1016/j.actamat.2005.03.054.

[33] J.A. Shaw, S. Kyriakides, Thermomechanical aspects of NiTi, J. Mech. Phys. Solids. 43 (1995) 1243-1281. doi:https://doi.org/10.1016/0022-5096(95)00024-D.

[34] H. Scherngell, A.C. Kneissl, Influence of the microstructure on the stability of the intrinsic two-way shape memory effect, Mater. Sci. Eng. A. 273-275 (1999) 400-403. doi:https://doi.org/10.1016/S0921-5093(99)00306-8.

[35] R. Lahoz, J.A. Puértolas, Training and two-way shape memory in NiTi alloys : influence on thermal parameters, J. Alloys Compd. $381 \quad$ (2004) 130-136. doi:10.1016/j.jallcom.2004.03.080.

[36] C.P. Frick, T.W. Lang, K. Spark, K. Gall, Stress-induced martensitic transformations and shape memory at nanometer scales, Acta Mater. 54 (2006) 2223-2234. doi:10.1016/j.actamat.2006.01.030.

[37] R. Xu, C. Bouby, H. Zahrouni, T.B.E.N. Zineb, H. Hu, 3D modeling of shape memory alloy fiber reinforced composites by multiscale finite element method, Compos. Struct. 200 (2018) 408-419. doi:https://doi.org/10.1016/j.compstruct.2018.05.108.

[38] J.S. Olsen, Z.L. Zhang, J.K. Hals, H. Lu, Effect of notches on the behavior of superelastic round-bar NiTi-specimens, Smart Mater. Struct. 20 (2011). doi:10.1088/0964$1726 / 20 / 2 / 025014$.

[39] A.L. McKelvey, R.O. Ritchie, Fatigue-crack propagation in Nitinol, a shape-memory and superelastic endovascular stent material, J. Biomed. Mater. Res. 47 (1999) 301-308. doi:10.1002/(SICI)1097-4636(19991205)47:3<301::AID-JBM3>3.0.CO;2-H.

[40] L. Mishnaevsky, E. Levashov, R.Z. Valiev, J. Segurado, I. Sabirov, N. Enikeev, S. Prokoshkin, A. V. Solov'yov, A. Korotitskiy, E. Gutmanas, I. Gotman, E. Rabkin, S. Psakh'e, L. Dluhoš, M. Seefeldt, A. Smolin, Nanostructured titanium-based materials for medical implants: Modeling and development, Mater. Sci. Eng. R Reports. 81 (2014) 1-19. doi:10.1016/j.mser.2014.04.002. 
[41] P.T. Mather, X. Luo, I.A. Rousseau, Shape Memory Polymer Research, Annu. Rev. Mater. Res. 39 (2009) 445-471. doi:10.1146/annurev-matsci-082908-145419.

[42] C. Liang, C.A. Rogers, E. Malafeew, Investigation of Shape Memory Polymers and Their Hybrid Composites, J. Intell. Mater. Syst. Struct. 8 (1997) 380-386. doi:10.1177/1045389X9700800411.

[43] W.M. Huang, B. Yang, Y. Zhao, Z. Ding, Thermo-moisture responsive polyurethane shapememory polymer and composites: a review, J. Mater. Chem. 20 (2010) 3367. doi:10.1039/b922943d.

[44] H. Tobushi, H. Hara, E. Yamada, S. Hayashi, Thermomechanical properties in a thin film of shape memory polymer of polyurethane series, Smart Mater. Struct. 5 (1996) 483-491. doi:10.1088/0964-1726/5/4/012.

[45] C. Poilane, P. Delobelle, C. Lexcellent, S. Hayashi, H. Tobushi, Analysis of the mechanical behavior of shape memory polymer membranes by nanoindentation, bulging and point membrane deflection tests, Thin Solid Films. 379 (2000) 156-165. doi:10.1016/S00406090(00)01401-2.

[46] A. Lendlein, S. Kelch, Shape-Memory Polymers, Angew. Chemie Int. Ed. 41 (2002) 2034. doi:10.1002/1521-3773(20020617)41:122034::AID-ANIE20343.0.CO2M.

[47] I.A. Rousseau, Challenges of shape memory polymers: A review of the progress toward overcoming SMP's limitations, Polym. Eng. Sci. 48 (2008) 2075-2089. doi:10.1002/pen.21213.

[48] S.N.R. Kantareddy, T.W. Simpson, Z. Ounaies, M. Frecker, 3D printing of shape changing polymer structures: design and characterization of materials, in: Proc. 26th Annu. Int. Solid Free. Fabr. Symp. Addit. Manuf. Conf., 2016: pp. 2224-2235.

[49] Y. Chen, D.C. Lagoudas, A constitutive theory for shape memory polymers. Part I Large deformations, J. Mech. Phys. Solids. 56 (2008) 1752-1765. doi:10.1016/j.jmps.2007.12.005.

[50] Z. Wang, C. Hansen, Q. Ge, S.H. Maruf, D.U. Ahn, H.J. Qi, Y. Ding, Programmable, PatternMemorizing Polymer Surface, Adv. Mater. 23 (2011) 3669-3673. doi:10.1002/adma.201101571.

[51] B.L. Volk, Three-Dimensional Modeling of Shape Memory Polymers Considering Finite Deformations and Heat Transfer, Texas A\&M University, 2012. https://oaktrust.library.tamu.edu/handle/1969.1/148140.

[52] J. Guo, J. Liu, Z. Wang, X. He, L. Hu, L. Tong, X. Tang, A thermodynamics viscoelastic constitutive model for shape memory polymers, J. Alloys Compd. 705 (2017) 146-155. doi:10.1016/j.jallcom.2017.02.142.

[53] I. Bellin, S. Kelch, R. Langer, A. Lendlein, Polymeric triple-shape materials, Proc. Natl. Acad. Sci. 103 (2006) 18043-18047. doi:10.1073/pnas.0608586103.

[54] M. Behl, A. Lendlein, Triple-shape polymers, J. Mater. Chem. 20 (2010) 3335. doi:10.1039/b922992b.

[55] Q. Ge, X. Luo, C.B. Iversen, P.T. Mather, M.L. Dunn, H.J. Qi, Mechanisms of triple-shape polymeric composites due to dual thermal transitions, Soft Matter. 9 (2013) 2212. 
doi:10.1039/c2sm27063c.

[56] S. Moon, I.J. Rao, S.A. Chester, Triple Shape Memory Polymers: Constitutive Modeling and Numerical Simulation, J. Appl. Mech. 83 (2016) 071008. doi:10.1115/1.4033380.

[57] S.E. Bakarich, R. Gorkin, M. in het Panhuis, G.M. Spinks, 4D Printing with Mechanically Robust, Thermally Actuating Hydrogels, Macromol. Rapid Commun. 36 (2015) 1211-1217. doi:10.1002/marc.201500079.

[58] J. Sun, X. Zhao, W.R.K. Illeperuma, O. Chaudhuri, K.H. Oh, D.J. Mooney, J.J. Vlassak, Z. Suo, Highly stretchable and tough hydrogels, Nature. 489 (2012) 133-136. doi:10.1038/nature11409.

[59] S. Naficy, R. Gately, R. Gorkin, H. Xin, G.M. Spinks, 4D Printing of Reversible Shape Morphing Hydrogel Structures, Macromol. Mater. Eng. $302 \quad$ (2017) 1600212. doi:10.1002/mame.201600212.

[60] S. Thakur, J. Chaudhary, V. Kumar, V.K. Thakur, Progress in pectin based hydrogels for water purification: Trends and challenges, J. Environ. Manage. 238 (2019) 210-223. doi:10.1016/j.jenvman.2019.03.002.

[61] R. Mohammadinejad, H. Maleki, E. Larrañeta, A.R. Fajardo, A.B. Nik, A. Shavandi, A. Sheikhi, M. Ghorbanpour, M. Farokhi, P. Govindh, E. Cabane, S. Azizi, A.R. Aref, M. Mozafari, M. Mehrali, S. Thomas, J.F. Mano, Y.K. Mishra, V.K. Thakur, Status and future scope of plant-based green hydrogels in biomedical engineering, Appl. Mater. Today. 16 (2019) 213-246. doi:10.1016/j.apmt.2019.04.010.

[62] S. Hong, D. Sycks, H.F. Chan, S. Lin, G.P. Lopez, F. Guilak, K.W. Leong, X. Zhao, 3D Printing of Highly Stretchable and Tough Hydrogels into Complex, Cellularized Structures, Adv. Mater. 27 (2015) 4035-4040. doi:10.1002/adma.201501099.

[63] J.S. Miller, K.R. Stevens, M.T. Yang, B.M. Baker, D.T. Nguyen, D.M. Cohen, E. Toro, A.A. Chen, P.A. Galie, X. Yu, R. Chaturvedi, S.N. Bhatia, C.S. Chen, Rapid casting of patterned vascular networks for perfusable engineered three-dimensional tissues, Nat. Mater. 11 (2012) 768-774. doi:10.1038/nmat3357.

[64] S. V Murphy, A. Skardal, A. Atala, Evaluation of hydrogels for bio-printing applications, J. Biomed. Mater. Res. Part A. 101A (2013) 272-284. doi:10.1002/jbm.a.34326.

[65] J.N. Hanson Shepherd, S.T. Parker, R.F. Shepherd, M.U. Gillette, J.A. Lewis, R.G. Nuzzo, 3D Microperiodic Hydrogel Scaffolds for Robust Neuronal Cultures, Adv. Funct. Mater. 21 (2011) 47-54. doi:10.1002/adfm.201001746.

[66] D. Han, Z. Lu, S.A. Chester, H. Lee, Micro 3D Printing of a Temperature-Responsive Hydrogel Using Projection Micro-Stereolithography, Sci. Rep. 8 (2018). doi:10.1038/s41598-018-20385-2.

[67] J. Wu, L. Huang, Q. Zhao, T. Xie, 4D Printing: History and Recent Progress, Chinese J. Polym. Sci. 36 (2018) 563-575. doi:10.1007/s10118-018-2089-8.

[68] H. Koerner, G. Price, N.A. Pearce, M. Alexander, R.A. Vaia, Remotely actuated polymer nanocomposites - stress-recovery of carbon-nanotube-filled thermoplastic elastomers, Nat. Mater. 3 (2004) 115-120. doi:10.1038/nmat1059. 
[69] Z. He, N. Satarkar, T. Xie, Y. Cheng, J.Z. Hilt, Remote Controlled Multishape Polymer Nanocomposites with Selective Radiofrequency Actuations, Adv. Mater. 23 (2011) 31923196. doi:10.1002/adma.201100646.

[70] T. Williams, M. Meador, S. Miller, D. Scheiman, P. Branch, M. Division, Effect of Graphene Addition on Shape Memory Behavior of Epoxy Resins, in: Soc. Adv. Mater. Process. Eng. (SAMPE); 17-20 Oct. 2011, Forth Worth, TX; United States, 2011.

[71] Y. Kim, J.Y. Cha, H. Ham, H. Huh, D. So, I. Kang, Preparation of piezoresistive nano smart hybrid material based on graphene, Curr. Appl. Phys. 11 (2011) S350-S352. doi:10.1016/j.cap.2010.11.022.

[72] S. Park, J. An, J.W. Suk, R.S. Ruoff, Graphene-Based Actuators, Small. 6 (2010) 210-212. doi:10.1002/smll.200901877.

[73] C.X. Guo, G.H. Guai, C.M. Li, Graphene Based Materials: Enhancing Solar Energy Harvesting, Adv. Energy Mater. 1 (2011) 448-452. doi:10.1002/aenm.201100119.

[74] X. Yang, X. Zhang, Y. Ma, Y. Huang, Y. Wang, Y. Chen, Superparamagnetic graphene oxide-Fe3O4 nanoparticles hybrid for controlled targeted drug carriers, J. Mater. Chem. 19 (2009) 2710. doi:10.1039/b821416f.

[75] X. Yu, H. Cheng, M. Zhang, Y. Zhao, L. Qu, G. Shi, Graphene-based smart materials, Nat. Rev. Mater. 2 (2017) 17046. doi:10.1038/natrevmats.2017.46.

[76] A. Lai, Z. Du, C.L. Gan, C.A. Schuh, Shape Memory and Superelastic Ceramics at Small Scales, Science (80-. ). 341 (2013) 1505-1508. doi:10.1126/science.1239745.

[77] T. Tsujimoto, T. Takayama, H. Uyama, Biodegradable Shape Memory Polymeric Material from Epoxidized Soybean Oil and Polycaprolactone, Polymers (Basel). 7 (2015) 2165-2174. doi:10.3390/polym7101506.

[78] S. Akbari, Y. Zhang, D. Wang, Q. Ge, 4D Printing and Its Biomedical Applications, 3D 4D Print. Biomed. Appl. Process Eng. Addit. Manuf. (2019) 343-372.

[79] F. Quadrini, E.A. Squeo, Solid-State Foaming of Epoxy Resin, J. Cell. Plast. 44 (2008) 161173. doi:10.1177/0021955X07082486.

[80] P. Rastogi, B. Kandasubramanian, Breakthrough in the printing tactics for stimuli-responsive materials: 4D printing, Chem. Eng. J. 366 (2019) 264-304. doi:10.1016/j.cej.2019.02.085.

[81] R.L. Truby, J.A. Lewis, Printing soft matter in three dimensions, Nature. 540 (2016) 371378. doi:10.1038/nature21003.

[82] Y. Yang, Y. Chen, Y. Wei, Y. Li, 3D printing of shape memory polymer for functional part fabrication, Int. J. Adv. Manuf. Technol. 84 (2016) 2079-2095. doi:10.1007/s00170-0157843-2.

[83] M.M. Mohebi, J.R.G. Evans, A Drop-on-Demand Ink-Jet Printer for Combinatorial Libraries and Functionally Graded Ceramics, J. Comb. Chem. 4 (2002) 267-274. doi:10.1021/cc010075e.

[84] X. Cui, D. Dean, Z.M. Ruggeri, T. Boland, Cell damage evaluation of thermal inkjet printed Chinese hamster ovary cells, Biotechnol. Bioeng. $106 \quad$ (2010) 963-969. 
doi:10.1002/bit.22762.

[85] M. Nakamura, A. Kobayashi, F. Takagi, A. Watanabe, Y. Hiruma, K. Ohuchi, Y. Iwasaki, M. Horie, I. Morita, S. Takatani, Biocompatible Inkjet Printing Technique for Designed Seeding of Individual Living Cells, Tissue Eng. 11 (2005) 1658-1666. doi:10.1089/ten.2005.11.1658.

[86] S.A. Nauroze, L. Novelino, M.M. Tentzeris, G.H. Paulino, Inkjet-printed “4D” tunable spatial filters using on-demand foldable surfaces, in: 2017 IEEE MTT-S Int. Microw. Symp., IEEE, 2017: pp. 1575-1578. doi:10.1109/MWSYM.2017.8058932.

[87] Y. Yang, Y. Chen, Y. Wei, Y. Li, Novel Design and Three-Dimensional Printing of Variable Stiffness Robotic Grippers, J. Mech. Robot. 8 (2016) 061010. doi:10.1115/1.4033728.

[88] S. Shaffer, K. Yang, J. Vargas, M.A. Di Prima, W. Voit, On reducing anisotropy in 3D printed polymers via ionizing radiation, Polymer (Guildf). 55 (2014) 5969-5979. doi:10.1016/j.polymer.2014.07.054.

[89] S.T. Ly, J.Y. Kim, 4D printing - fused deposition modeling printing with thermal-responsive shape memory polymers, Int. J. Precis. Eng. Manuf. Technol. 4 (2017) 267-272. doi:10.1007/s40684-017-0032-z.

[90] M. Bodaghi, A.R. Damanpack, W.H. Liao, Adaptive metamaterials by functionally graded 4D printing, Mater. Des. 135 (2017) 26-36. doi:10.1016/j.matdes.2017.08.069.

[91] J.A. Lewis, Direct Ink Writing of 3D Functional Materials, Adv. Funct. Mater. 16 (2006) 2193-2204. doi:10.1002/adfm.200600434.

[92] Q. Fu, E. Saiz, A.P. Tomsia, Direct ink writing of highly porous and strong glass scaffolds for load-bearing bone defects repair and regeneration, Acta Biomater. 7 (2011) 3547-3554. doi:10.1016/j.actbio.2011.06.030.

[93] J. Campbell, I. McGuinness, H. Wirz, A. Sharon, A.F. Sauer-Budge, Multimaterial and Multiscale Three-Dimensional Bioprinter, J. Nanotechnol. Eng. Med. 6 (2015) 021005. doi:10.1115/1.4031230.

[94] X. Kuang, K. Chen, C.K. Dunn, J. Wu, V.C.F. Li, H.J. Qi, 3D Printing of Highly Stretchable, Shape-Memory, and Self-Healing Elastomer toward Novel 4D Printing, ACS Appl. Mater. Interfaces. 10 (2018) 7381-7388. doi:10.1021/acsami.7b18265.

[95] M. Zarek, M. Layani, I. Cooperstein, E. Sachyani, D. Cohn, S. Magdassi, 3D Printing: 3D Printing of Shape Memory Polymers for Flexible Electronic Devices (Adv. Mater. 22/2016), Adv. Mater. 28 (2016) 4166-4166. doi:10.1002/adma.201670148.

[96] F.P.W. Melchels, J. Feijen, D.W. Grijpma, A review on stereolithography and its applications in biomedical engineering, Biomaterials. $31 \quad$ (2010) 6121-6130. doi:10.1016/j.biomaterials.2010.04.050.

[97] Y.Y.C. Choong, S. Maleksaeedi, H. Eng, J. Wei, P.C. Su, 4D printing of high performance shape memory polymer using stereolithography, Mater. Des. 126 (2017) 219-225. doi:10.1016/j.matdes.2017.04.049.

[98] R. Xie, D. Li, S. Chao, An inexpensive stereolithography technology with high power UVLED light, Rapid Prototyp. J. 17 (2011) 441-450. doi:10.1108/13552541111184170. 
[99] Q. Ge, A.H. Sakhaei, H. Lee, C.K. Dunn, N.X. Fang, M.L. Dunn, Multimaterial 4D Printing with Tailorable Shape Memory Polymers, Sci. Rep. 6 (2016) 1-11. doi:10.1038/srep31110.

[100] Y. Liu, J. Genzer, M.D. Dickey, “2D or not 2D”: Shape-programming polymer sheets, Prog. Polym. Sci. 52 (2016) 79-106. doi:10.1016/j.progpolymsci.2015.09.001.

[101] W. Wang, L. Yao, T. Zhang, C. Cheng, D. Levine, H. Ishii, Transformative Appetite: ShapeChanging Food Transforms from 2D to 3D by Water Interaction through Cooking, in: Proc. 2017 CHI Conf. Hum. Factors Comput. Syst. - CHI '17, ACM Press, New York, New York, USA, 2017: pp. 6123-6132. doi:10.1145/3025453.3026019.

[102] Q. Ge, C.K. Dunn, H.J. Qi, M.L. Dunn, Active origami by 4D printing, Smart Mater. Struct. 23 (2014). doi:10.1088/0964-1726/23/9/094007.

[103] E.T. Filipov, G.H. Paulino, T. Tachi, Origami tubes with reconfigurable polygonal crosssections, Proc. R. Soc. A Math. Phys. Eng. Sci. 472 (2016). doi:10.1098/rspa.2015.0607.

[104] Y. Liu, J. Park, R.J. Lang, A. Emami-Neyestanak, S. Pellegrino, M.S. Humayun, Y.C. Tai, Parylene origami structure for introcular implantation, in: 2013 Transducers Eurosensors XXVII 17th Int. Conf. Solid-State Sensors, Actuators Microsystems, TRANSDUCERS EUROSENSORS 2013, 2013: pp. 1549-1552. doi:10.1109/Transducers.2013.6627077.

[105] S. Felton, M. Tolley, E. Demaine, D. Rus, R. Wood, A method for building self-folding machines, Science (80-. ). 345 (2014) 644-646. doi:10.1126/science.1252610.

[106] Q. Zhang, J. Wommer, C. O'Rourke, J. Teitelman, Y. Tang, J. Robison, G. Lin, J. Yin, Origami and kirigami inspired self-folding for programming three-dimensional shape shifting of polymer sheets with light, Extrem. Mech. Lett. 11 (2017) 111-120. doi:10.1016/j.eml.2016.08.004.

[107] Y. Mao, K. Yu, M.S. Isakov, J. Wu, M.L. Dunn, H. Jerry Qi, Sequential Self-Folding Structures by 3D Printed Digital Shape Memory Polymers, Sci. Rep. 5 (2015) 1-12. doi:10.1038/srep13616.

[108] J.C. Breger, C. Yoon, R. Xiao, H.R. Kwag, M.O. Wang, J.P. Fisher, T.D. Nguyen, D.H. Gracias, Self-folding thermo-magnetically responsive soft microgrippers, ACS Appl. Mater. Interfaces. 7 (2015) 3398-3405. doi:10.1021/am508621s.

[109] M. Jamal, S.S. Kadam, R. Xiao, F. Jivan, T.M. Onn, R. Fernandes, T.D. Nguyen, D.H. Gracias, Bio-origami hydrogel scaffolds composed of photocrosslinked PEG bilayers, Adv. Healthc. Mater. 2 (2013) 1142-1150. doi:10.1002/adhm.201200458.

[110] D.G. Shin, T.H. Kim, D.E. Kim, Review of 4D printing materials and their properties, Int. J. Precis. Eng. Manuf. - Green Technol. 4 (2017) 349-357. doi:10.1007/s40684-017-0040-z.

[111] Q. Zhang, D. Yan, K. Zhang, G. Hu, Pattern Transformation of Heat-Shrinkable Polymer by Three-Dimensional (3D) Printing Technique, Sci. Rep. 5 (2015) 24-27. doi:10.1038/srep08936.

[112] S. Erkeçoglu, A.D. Sezer, S. Bucak, Smart Delivery Systems with Shape Memory and SelfFolding Polymers, in: Smart Drug Deliv. Syst., 2016. doi:10.5772/62199.

[113] K.K. Westbrook, P.T. Mather, V. Parakh, M.L. Dunn, Q. Ge, B.M. Lee, H.J. Qi, Two-way reversible shape memory effects in a free-standing polymer composite, Smart Mater. Struct. 
20 (2011). doi:10.1088/0964-1726/20/6/065010.

[114] H. Tamagawa, Thermo-responsive two-way shape changeable polymeric laminate, Mater. Lett. 64 (2010) 749-751. doi:10.1016/j.matlet.2009.12.053.

[115] Q. Yang, J. Fan, G. Li, Artificial muscles made of chiral two-way shape memory polymer fibers, Appl. Phys. Lett. 109 (2016). doi:10.1063/1.4966231.

[116] K. Yu, A. Ritchie, Y. Mao, M.L. Dunn, H.J. Qi, Controlled Sequential Shape Changing Components by 3D Printing of Shape Memory Polymer Multimaterials, Procedia IUTAM. 12 (2015) 193-203. doi:10.1016/j.piutam.2014.12.021.

[117] J. Leng, H. Lv, Y. Liu, S. Du, Comment on "Water-driven programable polyurethane shape memory polymer: Demonstration and mechanism" [Appl. Phys. Lett. 86, 114105 (2005)], Appl. Phys. Lett. 92 (2008) 206105. doi:10.1063/1.2936288.

[118] Y.C. Jung, H.H. So, J.W. Cho, Water-responsive shape memory polyurethane block copolymer modified with polyhedral oligomeric silsesquioxane, in: J. Macromol. Sci. Part B Phys., 2006: pp. 453-461. doi:10.1080/00222340600767513.

[119] D. Kokkinis, M. Schaffner, A.R. Studart, Multimaterial magnetically assisted 3D printing of composite materials., Nat. Commun. 6 (2015) 8643. doi:10.1038/ncomms9643.

[120] M.D. Dickey, Hydrogel composites: Shaped after print, Nat. Mater. 15 (2016) 379-380. doi:10.1038/nmat4608.

[121] J.W. Su, X. Tao, H. Deng, C. Zhang, S. Jiang, Y. Lin, J. Lin, 4D printing of a self-morphing polymer driven by a swellable guest medium, Soft Matter. 14 (2018) 765-772. doi:10.1039/c7sm01796k.

[122] H. Wei, Q. Zhang, Y. Yao, L. Liu, Y. Liu, J. Leng, Direct-write fabrication of 4D active shape-changing structures based on a shape memory polymer and its nanocomposite, in: $21 \mathrm{st}$ Int. Conf. Compos. Mater. Xi'an, 20-25th August 2017 4D, Xi'an, 2017. doi:10.1021/acsami.6b12824.

[123] X. Yu, S. Zhou, X. Zheng, T. Guo, Y. Xiao, B. Song, A biodegradable shape-memory nanocomposite with excellent magnetism sensitivity, Nanotechnology. 20 (2009). doi:10.1088/0957-4484/20/23/235702.

[124] A.M. Schmidt, Electromagnetic activation of shape memory polymer networks containing magnetic nanoparticles, Macromol. Rapid Commun. 27 (2006) 1168-1172. doi:10.1002/marc.200600225.

[125] P.R. Buckley, G.H. McKinley, T.S. Wilson, W. Small IV, W.J. Benett, J.P. Bearinger, M.W. McElfresh, D.J. Maitland, Inductively heated shape memory polymer for the magnetic actuation of medical devices, IEEE Trans. Biomed. Eng. 53 (2006) 2075-2083. doi:10.1109/TBME.2006.877113.

[126] J. Puig, C.E. Hoppe, L.A. Fasce, C.J. Pérez, Y. Piñeiro-Redondo, M. Bañobre-López, M.A. López-Quintela, J. Rivas, R.J.J. Williams, Superparamagnetic nanocomposites based on the dispersion of oleic acid-stabilized magnetite nanoparticles in a diglycidylether of bisphenol A-based epoxy matrix: Magnetic hyperthermia and shape memory, J. Phys. Chem. C. 116 (2012) 13421-13428. doi:10.1021/jp3026754. 
[127] H. Jiang, S. Kelch, A. Lendlein, Polymers move in response to light, Adv. Mater. 18 (2006) 1471-1475. doi:10.1002/adma.200502266.

[128] T.F. Scott, R.B. Draughon, C.N. Bowman, Actuation in crosslinked polymers via photoinduced stress relaxation, Adv. Mater. 18 (2006) 2128-2132. doi:10.1002/adma.200600379.

[129] Y. Yu, M. Nakano, T. Ikeda, Directed bending of a polymer film by light, Nature. 425 (2003) 145-145. doi:10.1038/425145a.

[130] F. Cheng, R. Yin, Y. Zhang, C.C. Yen, Y. Yu, Fully plastic microrobots which manipulate objects using only visible light, Soft Matter. 6 (2010) 3447-3449. doi:10.1039/c0sm00012d.

[131] A. Lendlein, H. Jiang, O. Jünger, R. Langer, Light-induced shape-memory polymers, Nature. 434 (2005) 879-882. doi:10.1038/nature03496.

[132] M. Irie, D. Kunwatchakun, Photoresponsive Polymers. 8. Reversible Photostimulated Dilation of Polyacrylamide Gels Having Triphenylmethane Leuco Derivatives, Macromolecules. 19 (1986) 2476-2480. doi:10.1021/ma00164a003.

[133] M.C. Serrano, G.A. Ameer, Recent insights into the biomedical applications of shapememory polymers, Macromol. Biosci. 12 (2012) 1156-1171. doi:10.1002/mabi.201200097.

[134] G.L. Raff, M.J. Gallagher, W.W. O’Neill, J.A. Goldstein, Diagnostic accuracy of noninvasive coronary angiography using 64-slice spiral computed tomography, J. Am. Coll. Cardiol. 46 (2005) 552-557. doi:10.1016/j.jacc.2005.05.056.

[135] N.B. Morgan, Medical shape memory alloy applications - The market and its products, Mater. Sci. Eng. A. 378 (2004) 16-23. doi:10.1016/j.msea.2003.10.326.

[136] T.W. Duerig, A.R. Pelton, D. Stöckel, The Use of Superelasticity in Medicine, MetallHeidelberg. 50 (1996). doi:10.1557/mrs2002.44.

[137] T. Duerig, A. Pelton, D. Stöckel, An overview of nitinol medical applications, Mater. Sci. Eng. A. 273-275 (2002) 149-160. doi:10.1016/s0921-5093(99)00294-4.

[138] C.M. Yakacki, R. Shandas, C. Lanning, B. Rech, A. Eckstein, K. Gall, Unconstrained recovery characterization of shape-memory polymer networks for cardiovascular applications, Biomaterials. 28 (2007) 2255-2263. doi:10.1016/j.biomaterials.2007.01.030.

[139] W. Small IV, P.R. Buckley, T.S. Wilson, W.J. Benett, J. Hartman, D. Saloner, D.J. Maitland, Shape memory polymer stent with expandable foam: A new concept for endovascular embolization of fusiform aneurysms, IEEE Trans. Biomed. Eng. 54 (2007) 1157-1160. doi:10.1109/TBME.2006.889771.

[140] C. Wischke, A. Lendlein, Shape-memory polymers as drug carriers-a multifunctional system, Pharm. Res. 27 (2010) 527-529. doi:10.1007/s11095-010-0062-5.

[141] A.T. Neffe, B.D. Hanh, S. Steuer, A. Lendlein, Polymer Networks Combining Controlled Drug Release, Biodegradation, and Shape Memory Capability, Adv. Mater. 21 (2009) 33943398. doi:10.1002/adma.200802333.

[142] R. Parke-Houben, C.H. Fox, L.L. Zheng, D.J. Waters, J.R. Cochran, C.N. Ta, C.W. Frank, Interpenetrating polymer network hydrogel scaffolds for artificial cornea periphery, J. Mater. 
Sci. Mater. Med. 26 (2015). doi:10.1007/s10856-015-5442-2.

[143] N.Q. Tran, Y.K. Joung, E. Lih, K.D. Park, In situ forming and rutin-releasing chitosan hydrogels as injectable dressings for dermal wound healing, Biomacromolecules. 12 (2011) 2872-2880. doi:10.1021/bm200326g.

[144] A. Song, A.A. Rane, K.L. Christman, Antibacterial and cell-adhesive polypeptide and poly(ethylene glycol) hydrogel as a potential scaffold for wound healing, Acta Biomater. 8 (2012) 41-50. doi:10.1016/j.actbio.2011.10.004.

[145] O. Robles-vazquez, I. Orozco-avila, J.C. Sánchez-díaz, E. Hernandez, An Overview of Mechanical Tests for Polymeric Biomaterial Scaffolds Used in Tissue Engineering, J. Res. Updat. Polym. Sci. 4 (2016) 168-178.

[146] B. Massoumi, M. Hatamzadeh, N. Firouzi, M. Jaymand, Electrically conductive nanofibrous scaffold composed of poly(ethylene glycol)-modified polypyrrole and poly( $\varepsilon$-caprolactone) for tissue engineering applications, Mater. Sci. Eng. C. 98 (2019) 300-310. doi:10.1016/j.msec.2018.12.114.

[147] M. Bao, X. Lou, Q. Zhou, W. Dong, H. Yuan, Y. Zhang, Electrospun biomimetic fibrous scaffold from shape memory polymer of PDLLA- co -TMC for bone tissue engineering, ACS Appl. Mater. Interfaces. 6 (2014) 2611-2621. doi:10.1021/am405101k.

[148] C. Sharma, A.K. Dinda, P.D. Potdar, C.F. Chou, N.C. Mishra, Fabrication and characterization of novel nano-biocomposite scaffold of chitosan-gelatin-alginatehydroxyapatite for bone tissue engineering, Mater. Sci. Eng. C. 64 (2016) 416-427. doi:10.1016/j.msec.2016.03.060.

[149] C.J. Liao, C.F. Chen, J.H. Chen, S.F. Chiang, Y.J. Lin, K.Y. Chang, Fabrication of porous biodegradable polymer scaffolds using a solvent merging/particulate leaching method, J. Biomed. Mater. Res. 59 (2002) 676-681. doi:10.1002/jbm.10030.

[150] W. Small IV, T.S. Wilson, W.J. Benett, J.M. Loge, D.J. Maitland, Laser-activated shape memory polymer intravascular thrombectomy device, Opt. Express. 13 (2005) 8204. doi:10.1364/OPEX.13.008204.

[151] M. Cabanlit, D. Maitland, T. Wilson, S. Simon, T. Wun, M.E. Gershwin, J. Van De Water, Polyurethane shape-memory polymers demonstrate functional biocompatibility in vitro, Macromol. Biosci. 7 (2007) 48-55. doi:10.1002/mabi.200600177.

[152] D.B. Kolesky, R.L. Truby, A.S. Gladman, T.A. Busbee, K.A. Homan, J.A. Lewis, 3D bioprinting of vascularized, heterogeneous cell-laden tissue constructs, Adv. Mater. 26 (2014) 3124-3130. doi:10.1002/adma.201305506.

[153] C.N. Ionita, M. Mokin, N. Varble, D.R. Bednarek, J. Xiang, K. V Snyder, A.H. Siddiqui, E.I. Levy, H. Meng, S. Rudin, Challenges and limitations of patient-specific vascular phantom fabrication using 3D Polyjet printing., Proc. SPIE--the Int. Soc. Opt. Eng. 9038 (2014) 90380M. doi:10.1117/12.2042266.

[154] S. Fusco, M.S. Sakar, S. Kennedy, C. Peters, S. Pane, D. Mooney, B.J. Nelson, Self-folding mobile microrobots for biomedical applications, in: Proc. - IEEE Int. Conf. Robot. Autom., 2014: pp. 3777-3782. doi:10.1109/ICRA.2014.6907406. 
[155] C. Kucukgul, S.B. Ozler, I. Inci, E. Karakas, S. Irmak, D. Gozuacik, A. Taralp, B. Koc, 3D bioprinting of biomimetic aortic vascular constructs with self-supporting cells, Biotechnol. Bioeng. 112 (2015) 811-821. doi:10.1002/bit.25493.

[156] J. Ishizawa, K. Imagawa, S. Minami, S. Hayashi, N. Miwa, Research on Application of Shape Memory Polymers to Space Inflatable Systems, in: Proc. 7th Int. Symp. Artif. Intell. Robot. Autom. Sp. I-SAIRAS., NARA, Japan, 2003.

[157] F.B. Koehler, W.D. Lyman, M.H. Summers, J.C. Danforth, Spacecraft with shape memory polymer deployment mechanism, US14/921,545, 2017. https://patents.google.com/patent/US20170113817A1/en.

[158] J. Hinkle, J. Lin, D. Kling, Design and Materials Study on Secondary Structures in Deployable Planetary and Space Habitats, in: 52nd AIAA/ASME/ASCE/AHS/ASC Struct. Struct. Dyn. Mater. Conf. 19th AIAA/ASME/AHS Adapt. Struct. Conf. 13t (p. 2024)., Denver, Colorado, 2014: pp. 1-10. doi:10.2514/6.2011-2024.

[159] R. Barrett, R. Taylor, P. Keller, D. Codell, L. Adams, Deployable Reflectors for Small Satellites, (n.d.) $1-6$.

[160] W. Sokolowski, Cold hibernated elastic memory self-deployable and rigidizable structure and method therefor, US09/771,455, 2004.

[161] W.M. Sokolowski, S.C. Tan, Advanced Self-Deployable Structures for Space Applications, J. Spacecr. Rockets. 44 (2007) 750-754. doi:10.2514/1.22854.

[162] K. Yu, S. Sun, L. Liu, Z. Zhang, Y. Liu, J. Leng, Novel deployable morphing wing based on SMP composite, in: Second Int. Conf. Smart Mater. Nanotechnol. Eng., 2009: p. 74932J. doi:10.1117/12.845408.

[163] J.N. Kudva, Overview of the DARPA Smart Wing Project, J. Intell. Mater. Syst. Struct. 15 (2004) 261-267. doi:10.1177/1045389X04042796.

[164] M. Meo, F. Marulo, M. Guida, S. Russo, Shape memory alloy hybrid composites for improved impact properties for aeronautical applications, Compos. Struct. 95 (2013) 756766. doi:10.1016/j.compstruct.2012.08.011.

[165] A. Sellitto, A. Riccio, Overview and Future Advanced Engineering Applications for Morphing Surfaces by Shape Memory Alloy Materials, Materials (Basel). 12 (2019) 708. doi:10.3390/ma12050708.

[166] N.S. Sonawane, J. Thangavelautham, Precision Pointing of Antennas in Space Using Arrays, in: Proc. 40th Annu. AAS Guid. Navig. Control Conf. 2017, 2107: pp. 1-12.

[167] F. Beavers, N. Munshi, M. Lake, A. Maji, K. Qassim, B. Carpenter, S. Rawal, Design and Testing of an Elastic Memory Composite Deployment Hinge for Spacecraft, in: 2012. doi:10.2514/6.2002-1452.

[168] D. Rus, M.T. Tolley, Design, fabrication and control of soft robots, Nature. 521 (2015) 467475. doi:10.1038/nature14543.

[169] M. López-Valdeolivas, D. Liu, D.J. Broer, C. Sánchez-Somolinos, 4D Printed Actuators with Soft-Robotic Functions, Macromol. Rapid Commun. $39 \quad$ (2018) 3-9. doi:10.1002/marc.201700710. 
[170] C. Laschi, M. Cianchetti, B. Mazzolai, L. Margheri, M. Follador, P. Dario, Soft robot arm inspired by the octopus, Adv. Robot. 26 (2012) 709-727. doi:10.1163/156855312X626343.

[171] B. Jin, H. Song, R. Jiang, J. Song, Q. Zhao, T. Xie, Programming a crystalline shape memory polymer network with thermo- and photo-reversible bonds toward a single-component soft robot, Sci. Adv. 4 (2018). doi:10.1126/sciadv.aao3865.

[172] K.C. Galloway, K.P. Becker, B. Phillips, J. Kirby, S. Licht, D. Tchernov, R.J. Wood, D.F. Gruber, Soft Robotic Grippers for Biological Sampling on Deep Reefs, Soft Robot. 3 (2016) 23-33. doi:10.1089/soro.2015.0019.

[173] R. Liu, X. Kuang, J. Deng, Y.C. Wang, A.C. Wang, W. Ding, Y.C. Lai, J. Chen, P. Wang, Z. Lin, H.J. Qi, B. Sun, Z.L. Wang, Shape Memory Polymers for Body Motion Energy Harvesting and Self-Powered Mechanosensing, Adv. Mater. 30 (2018) 1-8. doi:10.1002/adma.201705195.

[174] M. Manti, T. Hassan, G. Passetti, N. D’Elia, C. Laschi, M. Cianchetti, A Bioinspired Soft Robotic Gripper for Adaptable and Effective Grasping, Soft Robot. 2 (2015) 107-116. doi:10.1089/soro.2015.0009.

[175] B.S. Homberg, R.K. Katzschmann, M.R. Dogar, D. Rus, Haptic identification of objects using a modular soft robotic gripper, in: IEEE Int. Conf. Intell. Robot. Syst., 2015: pp. 1698 1705. doi:10.1109/IROS.2015.7353596.

[176] J. Shintake, V. Cacucciolo, D. Floreano, H. Shea, Soft Robotic Grippers, Adv. Mater. 30 (2018). doi:10.1002/adma.201707035.

[177] S. Shian, K. Bertoldi, D.R. Clarke, Dielectric Elastomer Based "grippers" for Soft Robotics, Adv. Mater. 27 (2015) 6814-6819. doi:10.1002/adma.201503078.

[178] F. Schreiber, M. Manns, J. Morales, Design of an additively manufactured soft ring-gripper, Procedia Manuf. 28 (2019) 142-147. doi:10.1016/j.promfg.2018.12.023.

[179] R. Vaidyanathan, D.W. Snyder, D.K. Schoenwald, N.S. Lam, D.S. Watson, V.B. Krishnan, R.D. Noebe, Shape memory-based actuators and release mechanisms therefrom, 8,209,976, 2012. https://patents.google.com/patent/US8209976B2/en.

[180] A. Villoslada, A. Flores, D. Copaci, D. Blanco, L. Moreno, High-displacement flexible Shape Memory Alloy actuator for soft wearable robots, in: Rob. Auton. Syst., 2015: pp. 91-101. doi:10.1016/j.robot.2014.09.026.

[181] H. Oh, T.D. Ta, R. Suzuki, M.D. Gross, Y. Kawahara, L. Yao, PEP ( 3D Printed Electronic Papercrafts ): An Integrated Approach for 3D Sculpting Paper-Based Electronic Devices, CHI. (2018) 1-12.

[182] L. Yao, R. Niiyama, J. Ou, S. Follmer, C. Della Silva, H. Ishii, PneUI : Pneumatically Actuated Soft Composite Material s for Shape Changing Interfaces, in: Proc. 26th Annu. ACM Symp. User Interface Softw. Technol., ACM, St. Andrews, Scotland, United Kingdom, 2013: pp. 13-22.

[183] J.S. Kim, D.Y. Lee, J.S. Koh, G.P. Jung, K.J. Cho, Component assembly with shape memory polymer fastener for microrobots, Smart Mater. Struct. 23 (2014). doi:10.1088/09641726/23/1/015011. 
[184] J.T.B. Overvelde, T.A. De Jong, Y. Shevchenko, S.A. Becerra, G.M. Whitesides, J.C. Weaver, C. Hoberman, K. Bertoldi, A three-dimensional actuated origami-inspired transformable metamaterial with multiple degrees of freedom, Nat. Commun. 7 (2016) 1-8. doi:10.1038/ncomms10929.

[185] Y.Y.F. Chan Vili, Investigating Smart Textiles Based on Shape Memory Materials, Text. Res. J. 77 (2007) 290-300. doi:10.1177/0040517507078794.

[186] K. Liu, J. Wu, G.H. Paulino, H.J. Qi, Programmable Deployment of Tensegrity Structures by Stimulus-Responsive Polymers, Sci. Rep. 7 (2017) 1-8. doi:10.1038/s41598-017-034126. [187] S. Beites, Morphological Behavior of Shape Memory Polymers Toward a Deployable, Adaptive Architecture, (n.d.) 121-128.

[187] S. Beites, Morphological Behavior of Shape Memory Polymers Toward a Deployable, Adaptive Architecture, (n.d.) 121-128.

[188] X. Lan, Y. Liu, H. Lv, X. Wang, J. Leng, S. Du, Fiber reinforced shape-memory polymer composite and its application in a deployable hinge, Smart Mater. Struct. 18 (2009). doi:10.1088/0964-1726/18/2/024002.

[189] J.H. Kang, E.J. Siochi, T.L. Turner, R.K. Penner, R. Thomas, S. Brown, A Study of Shape Memory Polymer Based Slat-Cove Filler, 2018.

[190] A.G. Tibert, S. Pellegrino, Deployable Tensegrity Reflectors for Small Satellites, J. Spacecr. Rockets. 39 (2008) 701-709. doi:10.2514/2.3867.

[191] A. Kumar, Emergence of Bioprinting in Tissue Engineering: A Mini Review, Adv. Tissue Eng. Regen. Med. Open Access. 1 (2016) 1-5. doi:10.15406/atroa.2016.01.00013.

[192] A. Lendlein, C. Wischke, How to accelerate biomaterial development? Strategies to support the application of novel polymer-based biomaterials in implantable devices, Expert Rev. Med. Devices. 8 (2011) 533-537. doi:10.1586/erd.11.39.

[193] A.B. Dababneh, I.T. Ozbolat, Bioprinting Technology: A Current State-of-the-Art Review, J. Manuf. Sci. Eng. 136 (2014) 061016. doi:10.1115/1.4028512. 
2019-10-16

\title{
4D printing of materials for the future: opportunities and challenges
}

\author{
Joshi, Siddharth
}

Elsevier

Joshi S, Rawat K, Karunakaran C, et al., (2020) 4D printing of materials for the future:

opportunities and challenges. Applied Materials Today, Volume 18, March 2020, Article number 100490

https://doi.org/10.1016/j.apmt.2019.100490

Downloaded from Cranfield Library Services E-Repository 